\title{
Non-Covalent Bonding Caught in Action: From Amorphous-to- Cocrystalline Molecular Thin Films
}

Received 00th January 20xx, Accepted 00th January 20xx DOI: $10.1039 / x 0 \times x 00000 x$

\author{
Olga Chovnik, ${ }^{\mathrm{a}}$ Sidney R. Cohen, ${ }^{\mathrm{b}}$ Iddo Pinkas, ${ }^{\mathrm{b}}$ Lothar Houben, ${ }^{\mathrm{b}}$ Tatiana E. Gorelik, ${ }^{\mathrm{c}}$ Yishay Feldman, \\ Linda J. W. Shimon, ${ }^{b}$ Mark A. Iron, ${ }^{b}$ Michal Lahav, ${ }^{* a}$ and Milko E. van der Boom*a
}

\section{Introduction}

Cocrystalline molecular materials often exhibit unique or advantageous properties that are absent in the amorphous phase or in unimolecular crystals. Although crystalline films consisting of one molecular component have found diverse applications (e.g., optoelectronic devices), ${ }^{1-6}$ there are relatively few examples are known with cocrystalline films. ${ }^{7-9}$ The on-surface formation of highly organized multicomponent materials consisting of molecules, polymers or biomolecules is still challenging as it is difficult to predict their structure and properties. The formation of such films involves not only the supramolecular interactions between the structurally different components but also weak interactions with the solid interface. Such interactions can affect packing, density and orientation. Orientation in such films is important and often crucial for the device performance as it enhances the material properties. ${ }^{10,11}$

Numerous studies have been devoted to the design of cocrystals with desired properties. ${ }^{12-15}$ For example, cocrystallization from solution is an effective method to tune the optical properties of crystals. ${ }^{16-26}$ Our group has reported crystalline materials prepared by physical vapor deposition (PVD), including crystal-to-cocrystal conversion using halogen-

a. Department of Molecular Chemistry and Materials Science, The Weizmann Institute of Science, Rehovot 7610001, Israel.

b. Department of Chemical Research Support. The Weizmann Institute of Science, Rehovot 7610001, Israel.

clectron Microscopy Group of Materials Science, Ulm University, UIm 89081, Germany.

† Electronic Supplementary Information (ESI) available: Experimental section, supplementary figures, ORTEP style figure of compound A2, crystallographic data as CCDC and Movies S1-S3. See DOI: 10.1039/x0xx00000x bonding (XB) on silicon substrates. 8,17 These results demonstrated the feasibility of this non-covalent interaction to generate ordered materials. XB remains one of the least studied and least used supramolecular interactions in the chemistry of molecular materials. ${ }^{18-23} \mathrm{XB}$ is a directional interaction favoring nearly linear donor-acceptor bond angles. ${ }^{24-27}$ Therefore, it has the potential to drive the organization of molecular components into pre-designed supramolecular assemblies. XBcrystallization has been studied mainly by formation of cocrystals from solution. Co-sublimation has been used by Bryce and coworkers as a rapid methodology to prepare a series of high quality XB-cocrystals, including crystal structures that were not accessible by other methods. ${ }^{28}$ Jones has applied mechanochemistry to generate XB-cocrystals. ${ }^{29}$ The progress in this field has been extensively reviewed by Resnati, Metrangolo and others. ${ }^{30-38}$ Some of these new XB-materials have interesting and useful properties. ${ }^{39-45}$

In this work, we present two examples of the conversion of amorphous organic films into cocrystalline coatings upon exposure to vapors of a XB-donor as shown in Scheme 1. The process involves consecutive physical vapor deposition (PVD) of the XB-acceptors $\mathbf{A}_{\mathbf{1}}$ or $\mathbf{A}_{\mathbf{2}}$, and the XB-donor $\mathbf{D}$. The unit-cell and space group parameters of the on-surface cocrystals were determined by 3D electron diffraction (ED) supported by second harmonic generation (SHG) measurements. We succeeded to follow this on-surface cocrystallization process and obtained mechanistic information that shows how the molecules rearrange. In situ monitoring by Raman spectroscopy revealed a gradual red-shift of the $v(\mathrm{C}-\mathrm{I})$ vibrational stretching frequency of the haloarene, indicating an increased strengthening of the $X B$ interaction. Optical microscopy shows that thermallyinduced motion and rearrangement of the XB-acceptor on the 
surface facilitates the gas-solid diffusion of the XB-donor into the amorphous film. This diffusion process involves formation of a halogen-bonded amorphous metastable phase prior to crystallization. Nanomechanical measurements reveal the importance of intermolecular interactions between the polypyridyl molecules present in the amorphous and crystalline phase. These non-covalent interactions influence the propensity for molecular rearrangements upon heating as indicated by the Young's modulus and surface energy of the film. This rearrangement affects both the sorption and the diffusion of the XB donor (D) into the film from the vapor phase. The on-surface assembly process results in a different crystalline packing arrangement of the components compared to bulk cocrystals grown from solution.

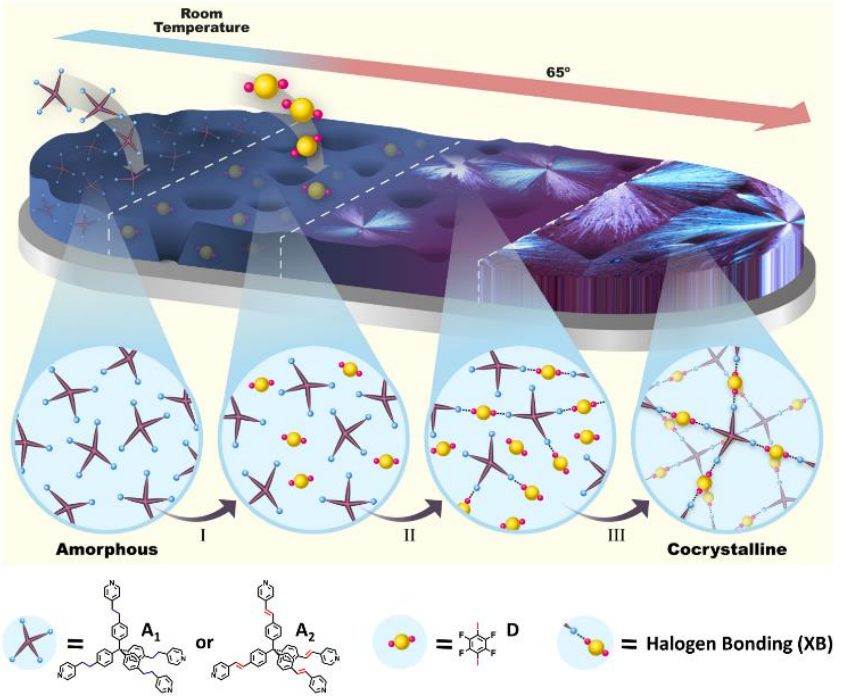

Scheme 1 Schematic representation of the three main steps of the solvent-free approach for preparing cocrystalline XB-based films. The XB acceptor (either $\mathbf{A}_{\mathbf{1}}$ or $\mathbf{A}_{\mathbf{2}}$ ) is deposited as an amorphous material on a silicon or quartz substrate by vacuum PVD, while keeping the substrate at room temperature. The amorphous $\mathbf{S}_{-} \mathbf{A}_{\mathbf{1}}$ or $\mathbf{S}_{-} \mathbf{A}_{\mathbf{2}}$ is exposed to vapors of the XB-donor (D) at $65^{\circ} \mathrm{C}$ (step I). This step initiates the diffusion of $\mathbf{D}$ into the film and its interaction with the acceptor molecules (step II, III), resulting in the formation of cocrystalline $\mathbf{S} \_\mathbf{A}_{1} \cdot \mathbf{D}$ or $\mathbf{S} \_\mathbf{A}_{2} \cdot \mathbf{D}$, respectively.

\section{Results and Discussion}

We selected nonplanar polypyridyl XB-acceptors with tetrahedral symmetry, as they form amorphous films. ${ }^{46}$ Moreover, we showed recently that $\mathbf{A}_{2}$ readily forms co-crystals with different fluoroiodides, including compound $D$ from solution. ${ }^{47}$ The three-dimensional halogen-bonded organic framework (XBOF) formed between molecules of $A_{2}$ and $D$ consists of nearly linear $\mathrm{N} \cdots \mathrm{l}$ bonds and is spanned with continuous channels occupied by solvent molecules. The electron-withdrawing fluorine substituents are known to increase the electrophilicity of the XB-donor (D) and thus the strength of the halogen bond. 48

The $X B$-acceptors $A_{1}$ and $A_{2}$ do not readily sublime under atmospheric pressure ${ }^{47}$ and therefore were deposited by vacuum PVD to form amorphous $\mathbf{S} \_\mathbf{A}_{\mathbf{1}}$ or $\mathbf{S} \_\mathbf{A}_{\mathbf{2}}$, respectively $(\mathbf{S}=$ surface). The amorphous-to-crystalline transformation of $\mathbf{S}_{-} \mathbf{A}_{1}$ or $\mathbf{S} \_\mathbf{A}_{\mathbf{2}}$ into $\mathbf{S} \_\mathbf{A}_{\mathbf{1}} \cdot \mathbf{D}$ or $\mathbf{S} \_\mathbf{A}_{\mathbf{2}} \cdot \mathbf{D}$ was achieved by subjecting the amorphous films to the vapors of $\mathbf{D}$ in a sealed cell at $65^{\circ} \mathrm{C}$ for $12 \mathrm{~h}$. Vacuum PVD is not required due to the sufficient volatility of $\mathbf{D}$ at ambient pressure.

We will first discuss the formation and characterization of S_A $\mathbf{A}_{\mathbf{1}}$ and $\mathbf{S} \_\mathbf{A}_{\mathbf{1}} \cdot \mathbf{D}$. The physical vapor deposition of compound $A_{1}$ on a silicon substrate covered with native oxide or on a fusedquartz substrate results in the formation of $\mathbf{S}_{-} \mathbf{A}_{\mathbf{1}}$. The growth of $S_{-} A_{1}$ was monitored with a quartz crystal microbalance (QCM). Unpolarized and polarized optical microscopy (Fig. 1a) and atomic force microscopy (AFM; Fig. 2a) indicated the formation of a homogeneous and amorphous film. The stability of $\mathbf{A}_{\mathbf{1}}$ under the applied reaction conditions was unambiguously confirmed by the following methods: (i) the Raman spectrum of $\mathbf{S} \_\mathbf{A}_{\mathbf{1}}$ is similar to the spectrum of a powder sample (Table S1, Fig. 3, blue and black spectra, respectively), (ii) UV-vis spectroscopy shows an absorbance at $\lambda_{\max } \approx 209 \mathrm{~nm}$, in agreement with measurements in solution $\left(\lambda_{\max } \approx 212 \mathrm{~nm}\right.$ in $n$ butanol, Fig. S1), (iii) reverse-phase HPLC (RP-HPLC) analysis of S_ $\mathbf{A}_{\mathbf{1}}$ by dissolving the deposited organic material (Fig. S2). Thermogravimetric analysis (TGA) and differential scanning calorimetry (DSC; Fig. S3) further showed the high thermal stability of $\mathbf{A}_{\mathbf{1}}$. The lack of any observable peaks in X-ray diffraction (XRD, Fig. 4, blue diffractogram) and the electron diffraction (ED, Fig. S4) confirm that this film is amorphous. The scanning electron microscopy (SEM) micrograph cross-section of a focused ion beam (FIB)-milled sample of $\mathbf{S}_{-} \mathbf{A}_{\mathbf{1}}$ reveals a continuous film with thickness of $\sim 117 \mathrm{~nm}$ (Fig. 5a).

Exposing $\mathbf{S}_{-} \mathbf{A}_{\mathbf{1}}$ to vapors of $\mathbf{D}$ at $65{ }^{\circ} \mathrm{C}$ for $12 \mathrm{~h}$ led to formation of $\mathbf{S}_{-} \mathbf{A}_{\mathbf{1}} \cdot \mathbf{D}$, as evidenced by microscopic morphological changes. The amorphous-to-crystalline transformation is clearly visible to the naked eye. Optical microscopy observations show spherulites that reach sizes of up to $2 \mathrm{~mm}$ and exhibit concentric bands of optical contrast (Fig. 1b, top and bottom, respectively). The temperature of $65^{\circ} \mathrm{C}$ was chosen to vaporize the halogen-bond donor (D) and to induce rearrangement of the halogen-bond acceptor on the surface (S_A1). Following the crystal growth with an optical microscope at $60{ }^{\circ} \mathrm{C}, 65{ }^{\circ} \mathrm{C}$ and $70{ }^{\circ} \mathrm{C}$ shows that the dimensions of the radially growing crystals increase with time, expanding faster at higher temperatures (Fig. S5). Working at $65{ }^{\circ} \mathrm{C}$ allowed us to follow the crystal growth in situ at a reasonable time scale (vide supra). The clear morphological and structural transformations between $\mathbf{S} \_\mathbf{A}_{\mathbf{1}}$ and $\mathbf{S} \_\mathbf{A}_{\mathbf{1}} \cdot \mathbf{D}$ are accompanied by an increase in the mean square surface roughness of the film as shown by AFM (from $\mathrm{S}_{q}=0.3$ to $\sim 6 \mathrm{~nm}$ for $1.5 \mu \mathrm{m} \times 1.5 \mu \mathrm{m}$ scan areas, Fig. 2 b). Raman spectroscopy showed the presence of XB interactions (Fig. 3, Table S1). This spectroscopic tool has been used to study and detect $X B$ in both the solid and liquid phases. ${ }^{49-52} \mathrm{~A}$ red-shift in frequency of $7 \mathrm{~cm}^{-1}$ of the symmetric $v(C-1)$ stretch and ring elongation band of $\mathbf{D}\left(v=157 \mathrm{~cm}^{-1}\right)$ is observed for $\mathbf{S} \_\mathbf{A}_{\mathbf{1}} \cdot \mathbf{D}(v=$ $\left.150 \mathrm{~cm}^{-1}\right)$. This intense lower frequency band could be explained by the weakening and hence lengthening of the $\mathrm{C}-\mathrm{I}$ bond due to $X B$. The position of this band is the same as for the cocrystal $\mathbf{A}_{\mathbf{1}} \cdot \mathbf{D}$ grown from solution (vide infra). 
a

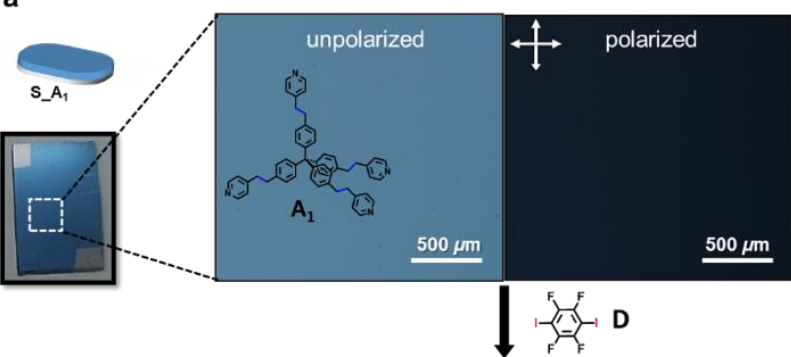

b

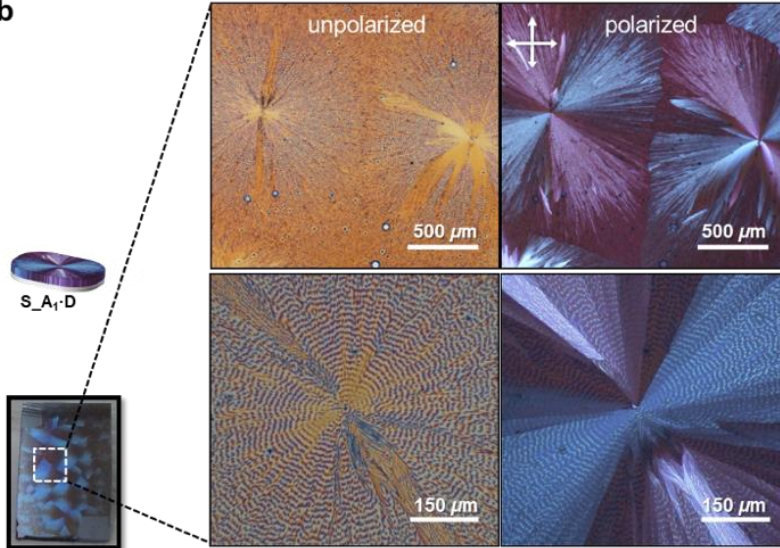

Fig. 1 Photographs (left) and optical micrographs (right) of $\mathbf{S} \_\mathbf{A}_{\mathbf{1}}(\mathrm{a})$ and $\mathbf{S} \_\mathbf{A}_{\mathbf{1}} \cdot \mathbf{D}(\mathrm{b})$ on silicon substrates. The two white corners on the photographs of $\mathbf{S}_{-} \mathbf{A}_{\mathbf{1}}$ and $\mathbf{S}_{-} \mathbf{A}_{1} \cdot \mathbf{D}$ (top-left and bottom-right) show the bare silicon substrates. Optical micrographs showing amorphous $\mathbf{S}_{-} \mathbf{A}_{\mathbf{1}}$ (a) and crystalline $\mathbf{S}_{-} \mathbf{A}_{\mathbf{1}} \cdot \mathbf{D}(\mathrm{b})$, without polarization (left) and between crossed polarizers (right) in the reflection mode. The zoomed in optical micrographs in (b, bottom) are of the spherulitic nucleation site and of concentric bands of optical contrast in $\mathbf{S}_{-} \mathbf{A}_{\mathbf{1}} \cdot \mathbf{D}$. The average distance between the observed concentric bands is $12.3 \pm 1.6 \mu \mathrm{m}$.
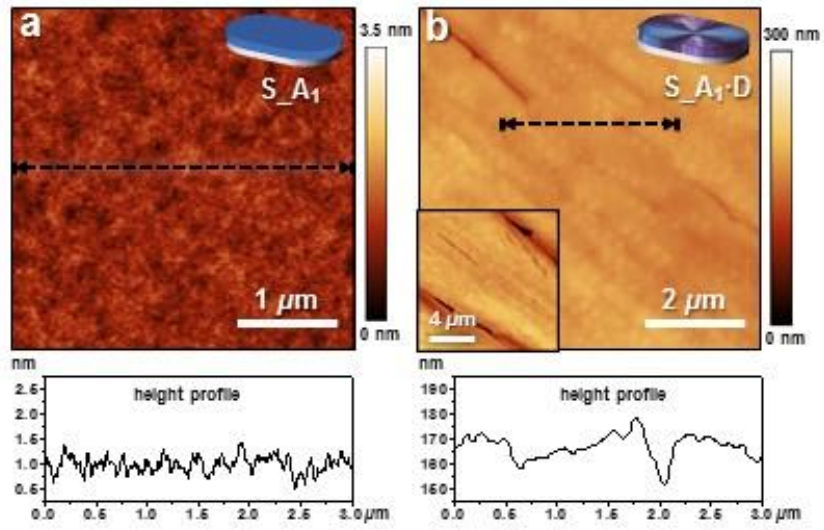

Fig. 2 Representative AFM topography images and height profiles of $\mathbf{S}_{-} \mathbf{A}_{1}(\mathbf{a})$ and S_A $\mathbf{A}_{1} \cdot \mathbf{D}(\mathrm{b})$ on a silicon substrate $(1 \mathrm{~cm} \times 1.5 \mathrm{~cm})$. The height profiles (bottom) were measured along the black lines in the corresponding topography images $(a, b)$.

Comparison of the solid-state structures of compound $\mathbf{D}\left(d_{\mathrm{C}-1}=\right.$ $2.075 \dot{A})^{53}$ and the cocrystal $\mathbf{A}_{1} \cdot \mathbf{D}\left(d_{\mathrm{C}-1}=2.089 \AA\right.$ and $2.104 \AA$, Fig. 6) gives direct evidence for lengthening of this covalent bond. The interaction is further supported by changes that occur to the pyridine ring manifested by peaks at $v=1002 \mathrm{~cm}^{-1}, 1011 \mathrm{~cm}^{-}$ 1 and $1071 \mathrm{~cm}^{-1}\left(\mathbf{S} \_\mathbf{A}_{\mathbf{1}} \cdot \mathbf{D}\right.$, Fig. 3, Table S1). These peaks are also observed in the spectra of cocrystal $\mathbf{A}_{1} \cdot \mathbf{D}\left(1003 \mathrm{~cm}^{-1}, 1011 \mathrm{~cm}^{-1}\right.$ and $\left.1070 \mathrm{~cm}^{-1}\right)$, and are at the noise level $\left(1002 \mathrm{~cm}^{-1}\right)$ or are weak $\left(1010 \mathrm{~cm}^{-1}\right.$ and $\left.1070 \mathrm{~cm}^{-1}\right)$ in the spectrum of $\mathbf{S} \_\mathbf{A}_{\mathbf{1}}$.

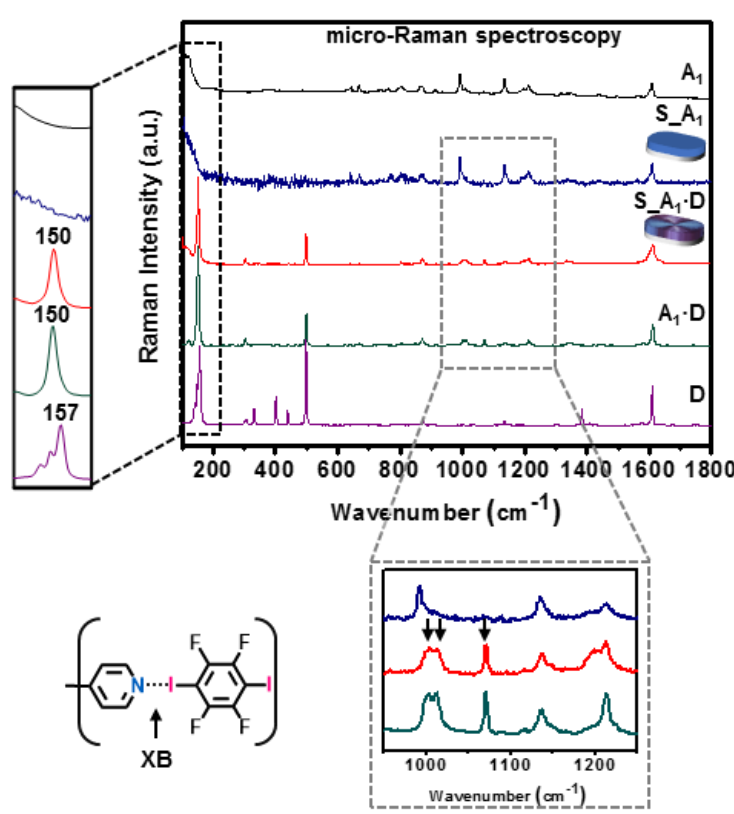

Fig. 3 Normalized Raman spectra (excitation at $\lambda=632.8 \mathrm{~nm}, 100 \times$ objective) of $\mathbf{S}_{-} \mathbf{A}_{\mathbf{1}}$ (blue) and $S_{-} A_{1} \cdot \mathbf{D}$ (red) on quartz $(0.8 \mathrm{~cm} \times 2.5 \mathrm{~cm})$ compared with the Raman spectra of powders of $\mathbf{A}_{\mathbf{1}}$ (black) and $\mathbf{D}$ (purple), and $\mathbf{A}_{\mathbf{1}} \cdot \mathbf{D}$ cocrystals (green). The expanded regions of the Raman spectra of $\mathbf{S}_{-} \mathbf{A}_{\mathbf{1}} \cdot \mathbf{D}$ show (left box) the appearance of a band at $150 \mathrm{~cm}^{-1}$ and its position relative to the symmetric $v_{\mathrm{C}-1}$ stretch and ring elongation band of $D$ at $157 \mathrm{~cm}^{-1}$, (bottom right box) the bands at $1002 \mathrm{~cm}^{-1}, 1011 \mathrm{~cm}^{-1}$ and $1071 \mathrm{~cm}^{-1}$ of $S_{-} A_{1} \cdot \mathbf{D}$ (indicated by arrows), as well as the presence of the bands at $1002 \mathrm{~cm}^{-1}$, $1011 \mathrm{~cm}^{-1}$ and $1071 \mathrm{~cm}^{-1}$ in the spectrum of cocrystal $A_{1} \cdot D$. Halogen bonding between $D$ and the pyridine ring of $\mathbf{A}_{\mathbf{1}}$ is described in the bottom left. The background has been subtracted from the Raman spectra of $\mathbf{S}_{-} \mathbf{A}_{\mathbf{1}}$ and $\mathbf{S} \_\mathbf{A}_{\mathbf{1}} \cdot \mathbf{D}$ after polynomial fitting. ${ }^{54}$

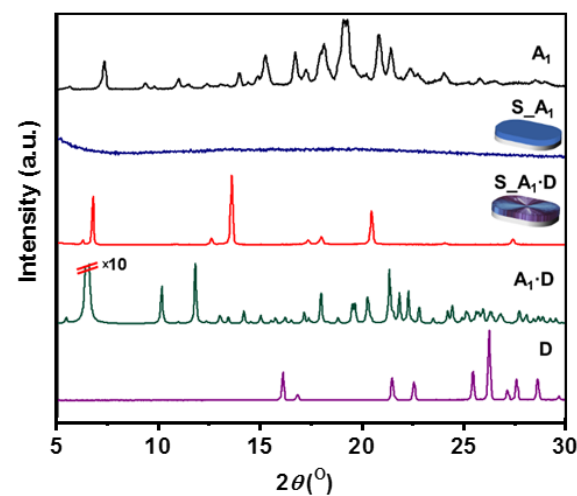

Fig. 4 Reflection XRD patterns of $\mathbf{S}_{-} \mathbf{A}_{\mathbf{1}}$ (blue) and $\mathbf{S}_{-} \mathbf{A}_{\mathbf{1}} \cdot \mathbf{D}$ (red) on $\mathrm{Si}(100)$ substrates measured in a symmetric mode compared with the XRD patterns of powders of $\mathbf{A}_{\mathbf{1}}$ (black) and $\mathbf{D}$ (purple), and a simulated XRD pattern of $\mathbf{A}_{1} \cdot \mathbf{D}$ cocrystals (green).

The ring breathing mode of pyridine is a good marker for both hydrogen and halogen bonding. ${ }^{55,56}$ The ring breathing frequency of pyridine $\left(992 \mathrm{~cm}^{-1}\right)$ in $\mathbf{A}_{\mathbf{1}}$ and $\mathbf{S}_{-} \mathbf{A}_{\mathbf{1}}$ shifts to the blue upon the formation of $\mathbf{A}_{\mathbf{1}} \cdot \mathbf{D}\left(1003 \mathrm{~cm}^{-1}\right)$ and $\mathbf{S} \_\mathbf{A}_{\mathbf{1}} \cdot \mathbf{D}\left(1002 \mathrm{~cm}^{-1}\right)$. This blue shift occurs due to the participation of the lone pair electrons of the pyridyl nitrogens in the $\mathrm{XB}$. The pyridine ring frequencies at $v=1011 \mathrm{~cm}^{-1}$ and $v=1071 \mathrm{~cm}^{-1}$ became visible upon halogen bonding. 
The presence of $\mathbf{D}$ was unambiguously confirmed: (i) the UV/Vis spectrum of $\mathbf{S} \_\mathbf{A}_{\mathbf{1}} \cdot \mathbf{D}$ shows the appearance of a new peak at $\lambda=$ $245 \mathrm{~nm}$ (Fig. S1, red). (ii) the reverse-phase high-performance liquid chromatogram of the redissolved $\mathbf{S} \_\mathbf{A}_{\mathbf{1}} \cdot \mathbf{D}$ shows elution of $\mathbf{A}_{\mathbf{1}}$ and $\mathbf{D}$ consistent with retention times observed for $\mathbf{S}_{-} \mathbf{A}_{\mathbf{1}}$ and $D$, respectively. The ratio of $\mathbf{A}_{1}: D=1: 1.7$ (Fig. S2, Table S2). Mass spectrometry (MS) analyses of $\mathbf{S} \mathbf{A}_{\mathbf{1}} \cdot \mathbf{D}$ dissolved in $\mathrm{CHCl}_{3}$ shows peaks at $m / e 741.54\left(\mathbf{A}_{1}\right)$ and 401.84 (D). An amorphous-tocrystalline transition of $\mathbf{S}_{-} \mathbf{A}_{\mathbf{1}}$ does not occur in the absence of compound D (Fig. S6). The morphology observed on FIB-milled samples is characterized by a grainy texture of the resulting film (grains of $\sim 1.5 \mu \mathrm{m}$ in width), with significant material rearrangement in the vicinity to the center of a radially growing crystal (Fig. 5b-e).

a
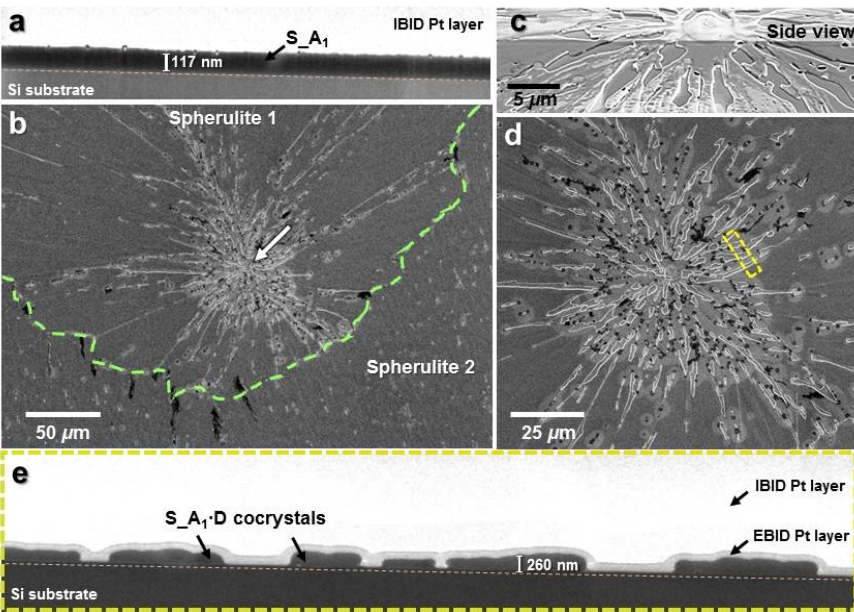

Fig. 5 SEM micrographs of $\mathbf{S}_{-} \mathbf{A}_{\mathbf{1}}$ and $\mathbf{S}_{-} \mathbf{A}_{\mathbf{1}} \cdot \mathbf{D}$ on silicon: (a) cross section of $\mathbf{S}_{-} \mathbf{A}_{\mathbf{1}}$; (b) region showing a boundary between two spherulites (dashed line); the nucleus is indicated by an arrow; zoom-in micrographs are shown as side (c) and top (d) views; (e) cross-section of $\mathbf{S} \_\mathbf{A}_{1} \cdot \mathbf{D}$ from the indicated area in (d). To prevent FIB-induced damage, a coating of Pt was applied (IBID = ion-beam induced deposition, EBID = electron-beam induced deposition).

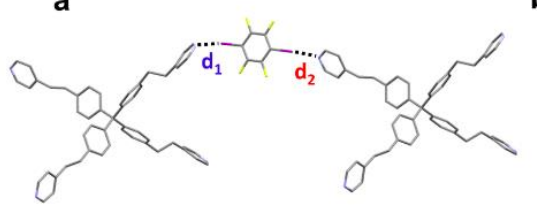

C

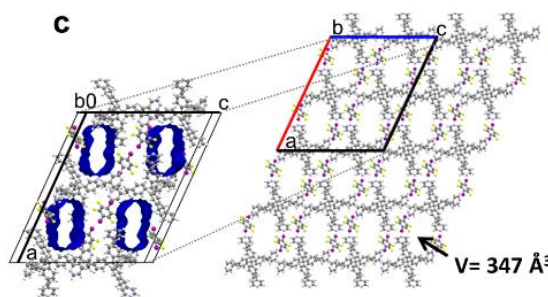

b

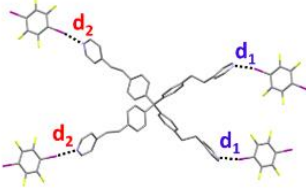

d

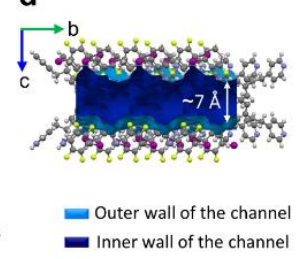

Fig. 6 (a, b) Partial view of the packing of cocrystal $\mathbf{A}_{1} \cdot \mathbf{D}$. (a) Compound $\mathbf{D}$ has two asymmetric $\mathrm{N} \cdots$ l bonds $\left(d_{1}=2.839 \AA\right.$; $d_{2}=2.754 \AA$ ) with $\mathbf{A}_{1}$. (b) Compound $\mathbf{A}_{1}$ has two sets of $\mathrm{N} \cdots$ I interactions with $\mathbf{D}$. (c) Ball-and-stick representations of the crystal lattice viewed down $b$ axis and (d) down $a$ axis showing continuous channels, each with a volume (V) of $347 \AA^{3}$ per unit cell. (c, d) Color scheme: carbon, gray; hydrogen, white; nitrogen, blue; fluorine, yellow; iodine, magenta.
The transformation of the amorphous $\mathbf{S}_{-} \mathbf{A}_{\mathbf{1}}$ into crystalline S_A $\mathbf{A}_{\mathbf{1}} \cdot \mathbf{D}$ is also evident from the appearance of strong Bragg reflections in the XRD diffraction pattern (Fig. 4, red diffractogram), which has strong Bragg reflection peaks. The XRD measurements reveal that $\mathbf{S} \_\mathbf{A}_{\mathbf{1}} \cdot \mathbf{D}$ is highly textured and its crystalline nature does not arise from unimolecular crystals composed solely from $\mathbf{A}_{\mathbf{1}}$ or $\mathbf{D}$ (Fig. $\mathbf{4}, \mathbf{S 7}$ ). The measurements further show that $\mathbf{S}_{-} \mathbf{A}_{\mathbf{1}} \cdot \mathbf{D}$ and $\mathbf{A}_{\mathbf{1}} \cdot \mathbf{D}$ have different packing arrangements. These differences are manifested in the XRD profile of $\mathbf{S} \mathbf{A}_{\mathbf{1}} \cdot \mathbf{D}$ with different peak positions from those calculated from the single crystal X-ray data of $\mathbf{A}_{\mathbf{1}} \cdot \mathbf{D}$ (Fig. $\mathbf{4}, \mathbf{S 7}$ ). These cocrystals $\mathbf{A}_{\mathbf{1}} \cdot \mathbf{D}$ grow from solution either as plates or needles, with needles elongated in the $b$ axis.

3D ED measurements in combination with second harmonic generation (SHG) studies confirmed the presence of a polymorphic structure for $\mathbf{S}_{-} \mathbf{A}_{\mathbf{1}} \cdot \mathbf{D}$ (Fig. 7).
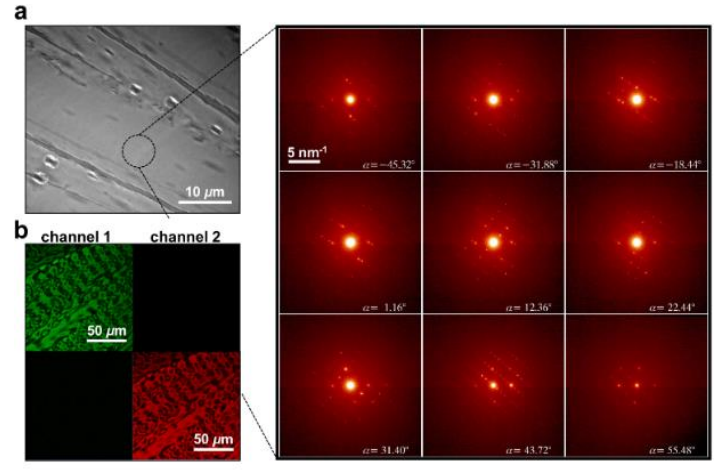

Fig. 7 (a) TEM micrograph of $\mathbf{S} \_\mathbf{A}_{1} \cdot \mathbf{D}$ grown on a grid with a hydrophilic $50 \mathrm{~nm}$ silicon nitride membrane $(0.5 \mathrm{~mm} \times 0.5 \mathrm{~mm}$ window). Representative electron diffraction tilt images (right) collected from the area marked in the corresponding TEM image (left) over a tilt angle range of $106^{\circ}$ (Movie S1). (b) Reflectance SHG micrographs of S_A $\mathbf{A}_{1} \cdot \mathbf{D}$ : (top) excitation at $\lambda=800 \mathrm{~nm}$, detection at $\lambda=395-405 \mathrm{~nm}$ (channel 1); (bottom) excitation at $\lambda=830 \mathrm{~nm}$, detection at $\lambda=478-572 \mathrm{~nm}$ (channel 2).

Table 1 Lattice parameters and refinement details of solution grown $\mathbf{A}_{\mathbf{1}} \cdot \mathbf{D}$ determined from single-crystal XRD (left) and $\mathbf{S}_{-} \mathbf{A}_{\mathbf{1}} \cdot \mathbf{D}$ determined from ED tilt series (right)

\begin{tabular}{lll}
\hline & $\begin{array}{l}\text { X-ray } \\
\text { diffraction } \\
\mathbf{A}_{\mathbf{1}} \cdot \mathbf{D}\end{array}$ & $\begin{array}{l}\text { Electron } \\
\text { diffraction } \\
\text { S_A } \mathbf{A}_{\mathbf{1}} \cdot \mathbf{D}\end{array}$ \\
\hline$a(\AA)$ & $35.5963(8)$ & 7.615 \\
$b(\AA)$ & $7.3398(2)$ & 34.188 \\
$c(\AA)$ & $29.9644(8)$ & 29.347 \\
$\alpha\left(^{\circ}\right)$ & 90 & 90.17 \\
$B\left(^{\circ}\right)$ & $115.267(2)$ & 97.26 \\
$V\left({ }^{\circ}\right)$ & 90 & 89.60 \\
$V\left(\AA^{3}\right)$ & $7079.8(3)$ & 7578.7 \\
Space group & $C 2 / c$ & $1 C C$ or C2/c \\
Resolution $(\AA)$ & 0.7 & 1.0 \\
$R_{\text {int }}(\%)$ & 4.37 & 13.26 \\
Completeness $(\%)$ & 99.80 & 31.61 \\
No. of independent input & & \\
reflections & 10799 & 1262 \\
\hline
\end{tabular}

${ }^{1}$ SHG measurements indicated a noncentrosymmetric, polar Cc space group; see text. 
The primitive unit cell parameters of $\mathbf{S} \_\mathbf{A}_{\mathbf{1}} \cdot \mathbf{D}$ extracted from the ED tilt series (Movie S1) were processed with the LePage MISSYM algorithm which allowed a geometrical transformation into a monoclinic $C$-centered unit cell, the unit cell parameters found are summarized in Table 1 . The full strucurre analysis of S_A $\mathbf{A}_{1} \cdot \mathbf{D}$ was not possible due to the low data completeness originating from the restricted tilt range of the goniometer.Due to the C-lattice centering and the apparent $c$-type glide plane signature of $\mathbf{S} \_\mathbf{A}_{\mathbf{1}} \cdot \mathbf{D}$ (Fig. S8) in 3D ED data, the on-surface polymorph could either crystallize in a non-centrosymmetric $C c$ or a centrosymmetric $C 2 / c$ space group. SHG microscopy was applied to further define the space group. Fig. 7b depicts the SHG signal generated by $\mathbf{S}_{-} \mathbf{A}_{\mathbf{1}} \cdot \mathbf{D}$, suggesting that the polymorphic structure belongs to the noncentrosymmetric, polar Cc space group.

To monitor in situ the amorphous-to-crystalline transformation of $\mathbf{S}_{-} \mathbf{A}_{\mathbf{1}}+\mathbf{D}_{(\mathrm{g})}$ to $\mathbf{S}_{-} \mathbf{A}_{\mathbf{1}} \cdot \mathbf{D}$ by optical microscopy and Raman spectroscopy, we have used a custom-made hermetically sealed cell (Fig. 8a). Both $\mathbf{S}_{-} \mathbf{A}_{\mathbf{1}}$ on a silicon substrate and the powder of $\mathbf{D}$ were placed in this cell. Then, the sealed cell was heated to $65^{\circ} \mathrm{C}$ and kept at this temperature for $12 \mathrm{~h}$. Optical micrographs were collected continuously during this period. (Fig. 8b, Movie S2). Areas having a darker contrast appear after $3 \mathrm{~min}$. A similar effect is observed for S_A $\mathbf{A}_{\mathbf{1}}$ in the absence of $\mathbf{D}$ (Fig. S9, Movie S3). These areas correspond to depleted material as inferred from a SEM micrograph of a cross section of a FIB-milled sample (Fig. S10). After 9 min of exposure of $S_{-} A_{1}$ to vapors of $D$, the color of the material changes from blue to yellow-orange, indicating changes in both composition and thickness. $\mathbf{S}_{-} \mathbf{A}_{\mathbf{1}}$ is likely saturated with $\mathbf{D}$ after $18 \mathrm{~min}$ as the color remains the same. ${ }^{57,58} \mathrm{~A}$ crystalline phase is observed after $19 \mathrm{~min}$ (see the lower left corner of the field of view in the images). The crystalline front propagates and consumes the amorphous phase at a lateral speed of $\sim 400 \mu \mathrm{m} / \mathrm{min}$. No changes are observed in the morphology of the crystalline film $\mathbf{S} \_\mathbf{A}_{1} \cdot \mathbf{D}$ after $\sim 30 \mathrm{~min}$, showing that the ex situ optical measurements (Fig. 1b) are representative of the monitored in situ reaction.

The amorphous-to-crystalline transformation was also followed in situ by micro-Raman spectroscopy. The evolution of two bands associated with the presence of $\mathbf{D}$ are observed (Fig. 9a). These bands are assigned to the $v(C-I)$ vibration and undergo a frequency shift to the red of $7 \mathrm{~cm}^{-1}\left(v=150 \mathrm{~cm}^{-1}\right)$ and $2 \mathrm{~cm}^{-1}\left(v=498 \mathrm{~cm}^{-1}\right)$ compared to their frequency in $D\left(v=157 \mathrm{~cm}^{-1}\right.$ and $v=500 \mathrm{~cm}^{-1}$, respectively, Table S1). The shift towards a lower wavenumber and the intensity of the band at $v=100-200 \mathrm{~cm}^{-1}$ (dashed box in Fig. 9a) is plotted in Fig. 9b. The measurement revealed an increase in intensity of this band with time until saturation is reached. The increase is preceded by an induction period of $\sim 9$ min corresponding to the time required to observe the presence of $\mathbf{D}$. Unreacted $\mathbf{D}$ was not observed at $v=$ $157 \mathrm{~cm}^{-1}$. The band position of $\mathbf{D}\left(v=153 \mathrm{~cm}^{-1}\right)$ suggests the occurrence of $X B$ before the formation of a crystalline material. The shift in frequency $\left(v=153 \mathrm{~cm}^{-1}\right.$ to $\left.v=150 \mathrm{~cm}^{-1}\right)$, as well the intensity increase stopped when the amorphous phase was transformed into the crystalline $\mathbf{S}_{-} \mathbf{A}_{\mathbf{1}} \cdot \mathbf{D}$. The gradual shift in the $v(C-I)$ from $v=157 \mathrm{~cm}$ ${ }^{1}$ (unreacted $\mathbf{D}$ ) to $v=153 \mathrm{~cm}^{-1}$ (amorphous $\mathbf{S} \_\mathbf{A}_{1} \cdot \mathbf{D}$ ) to $v=150 \mathrm{~cm}^{-1}$ (crystalline $\mathbf{S}_{-} \mathbf{A}_{\mathbf{1}} \cdot \mathbf{D}$ ) indicates that the overall process involves $\mathrm{XB}$ between the diffused $\mathbf{D}$ and $\mathbf{S}_{-} \mathbf{A}_{\mathbf{1}}$, and suggests strengthening of the $\mathrm{C}-\mid \cdots \mathrm{N}$ interactions during the amorphous-to-crystalline transformation. ${ }^{59}$ Both polarization and charge transfer interactions tend to elongate the $\mathrm{C}-\mathrm{I}$ bond and shift the $\mathrm{C}-\mathrm{I}$ stretching vibration to the red. The shift in this stretching vibration could be further explained by an enhanced electron transfer from the pyridine nitrogen to the antibonding orbital $\sigma^{*}(\mathbf{C}-\mathrm{I})$ of $\mathbf{D}$ upon its elongation, subsequently elongating it even more. ${ }^{49}$

a Hermetic cell for in situ microscopy and spectral measurements

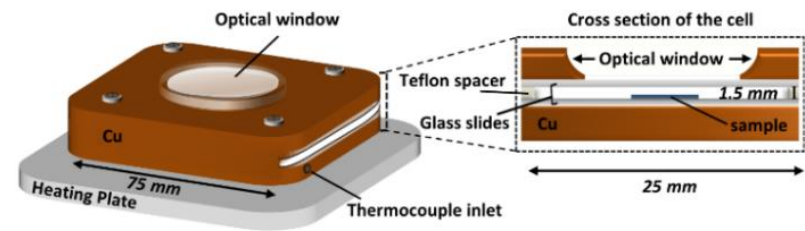

b In situ optical microscopy measurements
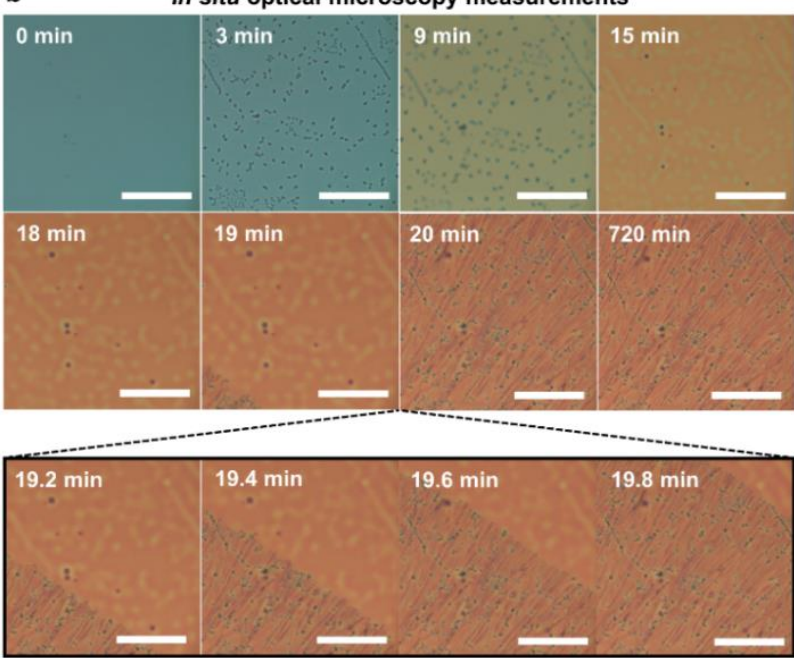

Fig. 8 (a) Drawing of the custom-made, gas-tight cell. (b) Optical microscopy observation of the transformation of amorphous $\mathbf{S}_{-} \mathbf{A}_{\mathbf{1}}$ into cocrystalline $\mathbf{S}_{-} \mathbf{A}_{\mathbf{1}} \cdot \mathbf{D}$ on a silicon substrate upon exposure to vapors of $\mathbf{D}$ at $65^{\circ} \mathrm{C}$; scale bar, $150 \mu \mathrm{m}$. The crystallization process was followed in situ by placing a sample in the cell employing a 10x objective (Movie S2). The propagation of the crystalline front is $\sim 400 \mu \mathrm{m} / \mathrm{min}$.

a b

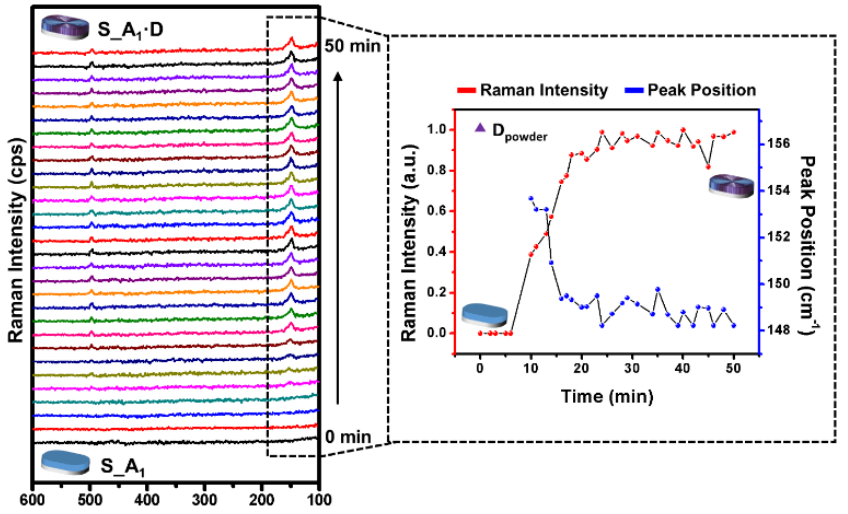

Wavelength $\left(\mathrm{cm}^{-1}\right)$

Fig. 9 (a) Time-series Raman spectra showing the transformation of amorphous $S_{-} A_{\mathbf{1}}$ upon exposure to $\mathbf{D}$ at $65^{\circ} \mathrm{C}$ into cocrystalline $\mathbf{S} \_\mathbf{A}_{\mathbf{1}} \cdot \mathbf{D}$ on a quartz. This transformation was monitored every $\sim 1.5$ min using a $50 \times$ objective and an excitation at $\lambda=633 \mathrm{~nm}$. The two evolving $v_{c-1}$ bands are in the wavelength range of $100-200 \mathrm{~cm}^{-1}$ and $450-550$ $\mathrm{cm}^{-1}$. (b) Raman data showing the frequency and normalized intensity behavior of the evolving $v_{\mathrm{C}-\mathrm{I}}$ band in the $100-200 \mathrm{~cm}^{-1}$ range. The position of this band is compared to the position of the symmetric $v_{\mathrm{C}-1}$ stretch and ring elongation band of $D$ at $157 \mathrm{~cm}^{-1}$. 
Mechanical properties of $\mathbf{S} \_\mathbf{A}_{\mathbf{1}}$ and $\mathbf{S} \_\mathbf{A}_{\mathbf{1}} \cdot \mathbf{D}$ (i.e., Young's modulus and adhesion) were measured using AFM and are summarized in Table S3. These properties are related to the molecular packing of thin films. ${ }^{60}$ The stiffness of the material is characterized by the elastic modulus. The adhesion force describes the interaction between the AFM tip and the surface and is an indication of the surface free energy. The measured modulus of $\mathbf{S} \_\mathbf{A}_{\mathbf{1}}$ is $9.1 \pm 0.8 \mathrm{GPa}$. After heating to $65^{\circ} \mathrm{C}$ for $12 \mathrm{~h}$ $\left(T>T_{g}\right)$ in absence of $D$, the modulus of $S_{-} A_{1}$ decreases to $4.5 \pm$ $0.3 \mathrm{GPa}$. One possible reason for the observed decrease in the Young's modulus of the heated $\mathbf{S}_{-} \mathbf{A}_{\mathbf{1}}$ is the formation of holes and material rearrangement, as was also observed by optical microscopy and SEM (Fig. S9, S10, respectively). Dewetting behavior is often observed in films that have been heated above their $T_{\mathrm{g} .}{ }^{61-64}$ The thermally-induced motion and rearrangement of $\mathbf{A}_{\mathbf{1}}$ on the surface is further supported by a change in the adhesion values of $\mathbf{S}_{-} \mathbf{A}_{\mathbf{1}}$ before and after heating $(87 \pm 3 \mathrm{nN}$ versus $43 \pm 2 \mathrm{nN}$, respectively). The thermally induced motion and rearrangement in $\mathbf{S}_{-} \mathbf{A}_{\mathbf{1}}$ is necessary for the diffusion of $\mathbf{D}$ and subsequent amorphous-to-cocrystalline transformation into $\mathbf{S} \_\mathbf{A}_{\mathbf{1}} \cdot \mathbf{D}$. In fact, exposure of $\mathbf{S}_{-} \mathbf{A}_{\mathbf{1}}$ to vapors of $\mathbf{D}$ at room temperature ( $T<T_{\mathrm{g}}$ of $\mathbf{A}_{1}$ ) resulted in the growth of $3 \mathrm{D}$ crystals on the surface of $\mathbf{S}_{-} \mathbf{A}_{\mathbf{1}}$ and the silicon substrate as shown by optical microscopy (Fig. S11). Single-crystal XRD analysis showed that these crystals are a polymorph of compound $\mathbf{D}, 65$ suggesting crystallization of $\mathbf{D}$ is kinetically preferred over the formation of $\mathbf{S} \_\mathbf{A}_{\mathbf{1}} \cdot \mathbf{D}$ at room temperature. For $\mathbf{S}_{-} \mathbf{A}_{\mathbf{1}} \cdot \mathbf{D}$, the Young's modulus and adhesion values are $10 \pm 5 \mathrm{GPa}$ and $67 \pm$ $19 \mathrm{nN}$, respectively (the large standard deviations are due to the roughness of the film). Both the Young's modulus and the adhesion values of $\mathbf{S}_{-} \mathbf{A}_{\mathbf{1}} \cdot \mathbf{D}$ are higher than those of the thermally treated $\mathbf{S}_{-} \mathbf{A}_{\mathbf{1}}$ (an increase of $124 \%$ and of $54 \%$, respectively). These changes could be due to the crystalline nature of $\mathbf{S} \_\mathbf{A}_{\mathbf{1}} \cdot \mathbf{D}$ accompanied by a change in the chemical composition of the crystalline film. The well-ordered $X B$ regions in $\mathbf{S} \_\mathbf{A}_{\mathbf{1}} \cdot \mathbf{D}$ resist compression due to electrostatic repulsion between molecular entities in the crystal, as well as the intermolecular interactions within the crystal.

Cocrystals are usually thermodynamically stable. ${ }^{66}$ Loss of a XB-donor upon storage in open air or heating has been reported to occur in some XB cocrystals. ${ }^{67}$ The cocrystalline $\mathbf{S} \_\mathbf{A}_{\mathbf{1}} \cdot \mathbf{D}$ can be considered as the equilibrium phase under an equilibrium vapor pressure of $\mathbf{D}$. Once this equilibrium condition is removed by opening the cell, the cocrystals slowly disassemble; they are not thermodynamically stable at ambient atmosphere. S_A $\mathbf{A}_{\mathbf{1}} \cdot \mathbf{D}$ loses its crystallinity over a period of 2 years (Fig. S12). This process is indicated by loss of the sharp diffraction peaks and appearance of an amorphous halo in the XRD profile, while retaining the overall macroscopic shape as seen by an optical microscope. The amorphization of the sample is attributed to loss of $\mathbf{D}$ from the film, as indicated by the disappearance of peaks originating either from $\mathbf{D}$ or the cocrystal in the Raman spectrum of a sample aged for 3 months. A similar Raman spectrum is obtained for $S_{-} A_{1} \cdot D$ kept at $100{ }^{\circ} \mathrm{C}$ for $25 \mathrm{~h}$, showing that $\mathbf{D}$ can be removed from the film by heating.

We evaluated the dependence of the amorphous to co-crystal conversion on the molecular properties of the acceptor. Therefore, acceptor $\left(\mathbf{A}_{2}\right)$ (the conjugated analogue of $\mathbf{A}_{1}$; Scheme $\mathbf{1}$, Fig. S13) was used to generate films $\mathbf{S}_{-} \mathbf{A}_{\mathbf{2}}$ and $\mathbf{S}_{-} \mathbf{A}_{\mathbf{2}} \cdot \mathbf{D}$. The inherent intramolecular structural differences between the two types of acceptor molecules $\mathbf{A}_{\mathbf{1}}$ and $\mathbf{A}_{\mathbf{2}}\left(\mathrm{H}_{2} \mathrm{C}-\mathrm{CH}_{2}\right.$ versus $\left.\mathrm{HC}=\mathrm{CH}\right)$ could introduce inequalities in their rotational motion and affect the electron density of the pyridine groups. These are factors that might affect both the structural properties of the amorphous films and the subsequent cocrystallization process. Hindering of rotational or any other type of molecular motion, achieved via inter- and intramolecular interactions or structurally rigid moieties, increases the glass transition temperature $\left(T_{\mathrm{g}}\right) .{ }^{68}$ Compound $\mathbf{A}_{\mathbf{2}}$ does not exhibit any phase transition between $15^{\circ} \mathrm{C}$ and $170{ }^{\circ} \mathrm{C}$ in the DSC thermogram, whereas $\mathbf{A}_{\mathbf{1}}$ does exhibit such transitions (Fig. S3, S1ㄴ). The film $\mathbf{S}_{-} \mathbf{A}_{\mathbf{2}}$ is homogeneous, smooth and amorphous as judged by optical microscopy, AFM and XRD (Fig. 10, S15-S16). The Raman spectrum of $\mathbf{S}_{-} \mathbf{A}_{\mathbf{2}}$ is different from the data observed for the powder of $\mathbf{A}_{\mathbf{2}}$ (Table S1, Fig. S17). The spectral differences are related to bands associated with the pyridine and the phenyl rings and include: i) shift of the peak at $1143 \mathrm{~cm}^{-1}$ to $1139 \mathrm{~cm}$ , at $1337 \mathrm{~cm}^{-1}$ to $1331 \mathrm{~cm}^{-1}$, and at $1596 \mathrm{~cm}^{-1}$ to $1602 \mathrm{~cm}^{-1}$; ii) appearance of a peak at $1000 \mathrm{~cm}^{-1}$; iii) change in the ratio between the relative intensities of peaks at $1596 \mathrm{~cm}^{-1}$ and $1633 \mathrm{~cm}^{-1}$ in $A_{2}$ (1: 1.8 , respectively), and of peaks at $1602 \mathrm{~cm}^{-1}$ and $1633 \mathrm{~cm}^{-1}$ in $S_{-} A_{2}$ (1 : 0.7, respectively). These changes suggest that the deposited $\mathbf{A}_{\mathbf{2}}$ molecules interact through the pyridine and the phenyl rings. The $\mathrm{N}$ (pyridyl) $\cdots \mathrm{H}-\mathrm{C}$ (pyridyl/aryl) interactions have been reported to occur in the 2D network of a XB-acceptor 1,3,5-tris(pyridine-4ylethynyl)benzene. ${ }^{69}$ Frequency shifts were not observed for the peaks of the vinyl group $\left(1345 \mathrm{~cm}^{-1}, 1633 \mathrm{~cm}^{-1}\right),{ }^{70}$ suggesting that $\pi$ $\pi$ interactions are not likely to occur in $\mathbf{S}_{-} \mathbf{A}_{\mathbf{2}}$.

The formation of a more rigid film of $\mathbf{A}_{\mathbf{2}}$ than of $\mathbf{A}_{\mathbf{1}}$ is supported by nanomechanical measurements. Heating to $65^{\circ} \mathrm{C}$ for $12 \mathrm{~h}$ does not change the Young's modulus of $\mathbf{S}_{-} \mathbf{A}_{\mathbf{2}}$ nor the magnitude of the adhesion force (decrease by 3\%, Table S3). The rigidity of $\mathbf{S}_{-} \mathbf{A}_{2}$ could be explained by intermolecular interactions, as is supported by Raman spectroscopy data presented above. No obvious changes are observed in the optical microscope images or Raman spectrum of the thermally treated $\mathbf{S}_{-} \mathbf{A}_{\mathbf{2}}$ (Fig. S18). Moreover, $\mathbf{S}_{-} \mathbf{A}_{\mathbf{2}}$ remains in its amorphous state as evident from the absence of peaks in the diffractogram, and the film does not dewet the substrate as S_A $\mathbf{1}$ does.

An amorphous-to-crystalline transformation also occurs upon exposing $\mathbf{S}_{-} \mathbf{A}_{2}$ to vapors of $\mathbf{D}$ at $65^{\circ} \mathrm{C}$. Optical microscopy showed that the spherulites in $\mathbf{S} \_\mathbf{A}_{\mathbf{2}} \cdot \mathbf{D}$ are $\sim 10 \times$ smaller than the spherulites in $\mathbf{S} \_\mathbf{A}_{1} \cdot \mathbf{D}$ with the largest observed measuring only $100 \mu \mathrm{m}$ across (Fig. 10). The spherulites cover the surface of the substrate while a few crystals of $\mathbf{D}$, indicated by white arrows, are seen on top of the spherulitic film. The transformation of the amorphous $\mathbf{S} \_\mathbf{A}_{\mathbf{2}}$ into the crystalline $\mathbf{S} \_\mathbf{A}_{\mathbf{2}} \cdot \mathbf{D}$ is also evident from XRD diffraction measurements that showed the emergence of wide Bragg reflection peaks as expected from the optical microscopy observations mentioned above (Fig. S16, S19). Those peaks do not correspond to crystallites of $\mathbf{A}_{\mathbf{2}}$ or $\mathbf{D}$, nor to the $\mathbf{A}_{2} \cdot \mathbf{D}$ crystal grown from solution (Fig. S19). The presence of $\mathbf{D}$ is indicated by UV/Vis spectroscopy showing a peak at $\lambda=245 \mathrm{~nm}$ and further confirmed by RP-HPLC measurements (Fig. S20, S21). 


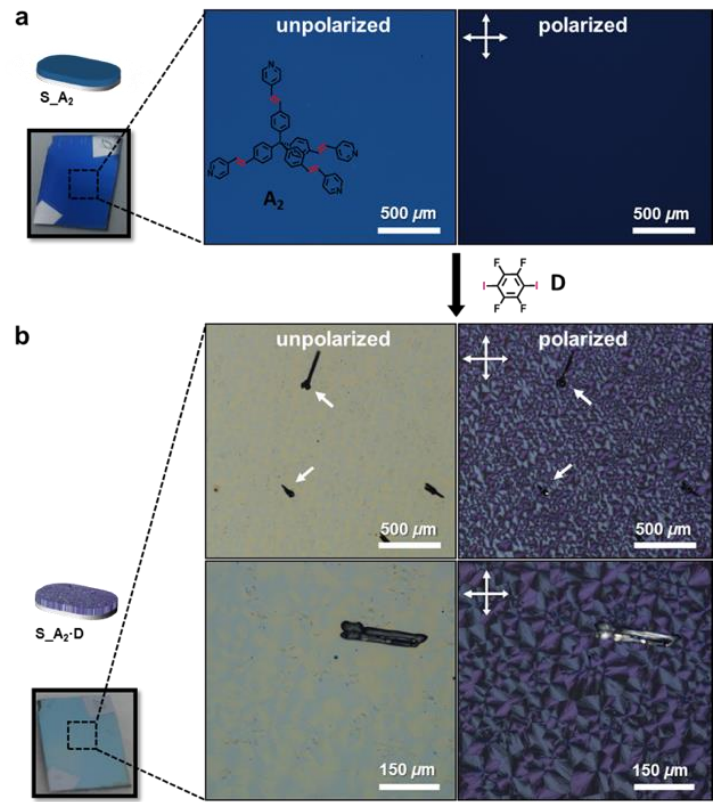

Fig. 10 Optical micrographs showing the changes experienced by $\mathbf{S}_{-} \mathbf{A}_{\mathbf{2}}$ (a) in presence of vapors of $\mathbf{D}(\mathrm{b})$, viewed without polarization (left) and between crossed polarizers (right) in reflection mode. Exposure of $\mathbf{S}_{-} \mathbf{A}_{\mathbf{2}}$ to compound $\mathbf{D}$ at $65^{\circ} \mathbf{C}$. The white arrows indicate crystals of $\mathbf{D}$ observed on the surface of $\mathbf{S}_{-} \mathbf{A}_{\mathbf{2}} \cdot \mathbf{D}$.

The SEM micrographs of cross-sections of FIB-milled $\mathbf{S}_{-} \mathbf{A}_{\mathbf{2}}$ and S_A $\mathbf{A} \cdot \mathbf{D}$ show continuous films (Fig. S22, 11), and an increase in film thickness of $\sim 30 \mathrm{~nm}$ occurred upon the exposure of $\mathbf{S}_{-} \mathbf{A}_{\mathbf{2}}$ to $\mathbf{D}$. Raman spectroscopy shows different peak positions for the $v(C-1)$ stretch of S_A $\mathbf{A}_{2} \cdot \mathbf{D}\left(150 \mathrm{~cm}^{-1}\right)$ and $\mathbf{A}_{2} \cdot \mathbf{D}$ cocrystals grown from solution $(150 \mathrm{~cm}$ $\left.{ }^{1}\right)$ compared to $D\left(157 \mathrm{~cm}^{-1}\right)$ (Fig. S17), indicating the formation of $X B$ interactions. Interestingly, the formation of $\mathbf{S} \_\mathbf{A}_{2} \cdot \mathbf{D}$ decreases the value of the Young's modulus (48\%) and the adhesion (37\%) (Table S3). Here, the stiffening due to enhanced order proposed for the S_A $\mathbf{A}_{1} \cdot \mathbf{D}$ is much weaker and, in fact, the presence of $\mathbf{D}$ weakens the overall stiffness of the internal bonds. Diffusion of $D$ into $S_{-} A_{2}$ results in $\mathrm{XB}$ interactions, molecular rearrangements, and changes in packing interactions which could result in a more compliant structure.

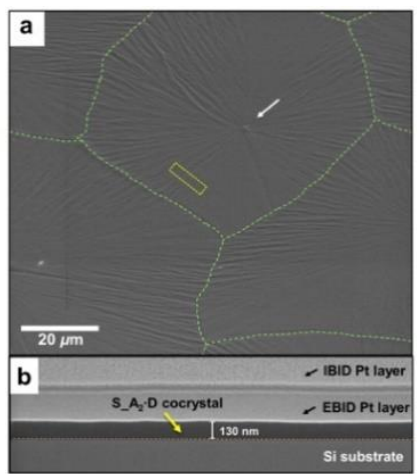

Fig. 11 (a) SEM micrograph of $S_{-} A_{2} \cdot D$ on a silicone substrate. The dashed, green line shows the boundary between spherulites with the nucleus indicated by a white arrow. (b) Focused ion beam (FIB)-milled cross section of $\mathbf{S} \_\mathbf{A}_{\mathbf{2}} \cdot \mathbf{D}$ (of the yellow box in a). IBID = ion-beam induced deposition, EBID = electron-beam induced deposition.

We believe that the different degree of flexibility, and to a lesser extent, the nucleophilicity of the acceptors in the amorphous $\mathbf{S}_{-} \mathbf{A}_{\mathbf{1}}$ and $\mathbf{S}_{-} \mathbf{A}_{\mathbf{2}}$ films account for the difference in structures formed upon interaction with $\mathbf{D}$. The nucleophilicity of $\mathbf{A}_{\mathbf{1}}$ and $\mathbf{A}_{\mathbf{2}}$ is manifested by the electron donating ability of their pyridine nitrogen atoms. To evaluate this quantity we used density functional theory (DFT) calculations and nuclear magnetic resonance (NMR) spectroscopy. The electron density maps of $\mathbf{A}_{\mathbf{1}}$ and $\mathbf{A}_{\mathbf{2}}$ are presented in Fig. 12, and the associated partial atomic charges are summarized in Table $\mathbf{2}$. The DFT calculations show a slightly higher $(0.004$ e) electron density on the nitrogen atoms of the pyridine ring of the non-conjugated moieties of $\mathbf{A}_{1}$ (Table 2). ${ }^{1} \mathrm{H}{ }^{15} \mathrm{~N}$ HMQC NMR spectroscopy shows minor differences for the pyridine nitrogen atoms in $\mathbf{A}_{\mathbf{1}}$ and $\mathbf{A}_{\mathbf{2}}(\delta=$ $298 \mathrm{ppm}$ versus $\delta=302 \mathrm{ppm}$, respectively, Table 2, Fig. S23). A comparable difference $(4.5 \mathrm{ppm})$ in ${ }^{15} \mathrm{~N}$ NMR was reported for alkyl versus vinyl pyridine. ${ }^{71}$ Likewise, ${ }^{1} \mathrm{H}$ NMR shows a minor difference for the pyridine $\alpha$-hydrogen atoms ( $\delta=8.5 \mathrm{ppm}$ versus $\delta=8.6 \mathrm{ppm}$, respectively). The NMR measurements and DFT calculations suggest similar nucleophilicity for $\boldsymbol{A}_{\mathbf{1}}$ and $\boldsymbol{A}_{\mathbf{2}}$. This observation is further supported by the equal strength of the $X B$ interaction in $A_{1} \cdot D$ and $A_{2} \cdot D$ reflected in the equal reduction $\left(7 \mathrm{~cm}^{-1}\right)$ in the $C-1$ stretching vibration in $\mathbf{D}\left(157 \mathrm{~cm}^{-1}\right)$, as the strength of the $X B$ interaction is influenced by the nucleophilicity of the XB-acceptor. ${ }^{59,72}$

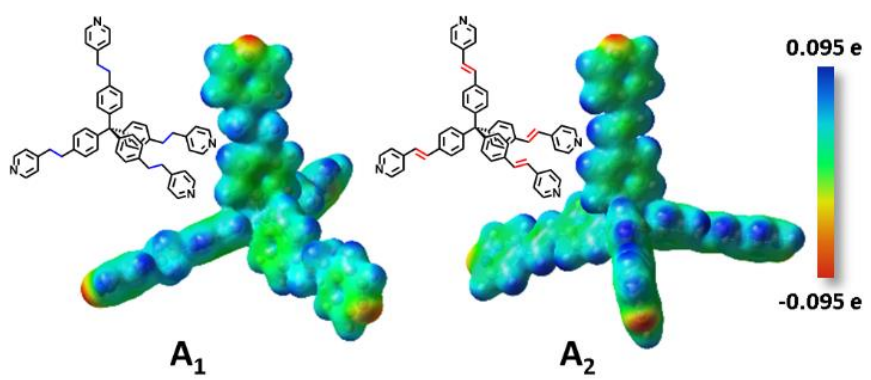

Fig. 12 Electrostatic potential maps of the DFT-optimized structures of $\mathbf{A}_{\mathbf{1}}$ and $\mathbf{A}_{\mathbf{2}}$.

Table 2 Hirshfeld-I partial atomic charges on the sub-molecular units (left), and the experimental ${ }^{15} \mathrm{~N}$ and ${ }^{1} \mathrm{H}$ NMR (pyridine $\alpha$-hydrogen) chemical shifts of the pyridine rings of $\mathbf{A}_{\mathbf{1}}$ and $\mathbf{A}_{\mathbf{2}}$ (right).

\begin{tabular}{ccccc|ccc}
\hline & Pyr & $\boldsymbol{N}_{\text {pyr }}$ & $\mathrm{CH}_{\mathrm{x}}-\mathrm{CH}_{\mathrm{x}}$ & $\mathrm{Ph}$ & & $\delta\left(\boldsymbol{N}_{\text {pyr }}\right)$ & $\delta\left(\boldsymbol{\alpha}-\boldsymbol{H}_{\text {pyr }}\right)$ \\
\hline $\mathbf{A}_{\mathbf{1}}$ & 0.01 & -0.343 & -0.046 & 0.036 & $\mathbf{A}_{1}$ & 298.43 & 8.46 \\
$\mathbf{A}_{2}$ & -0.008 & -0.339 & 0.009 & 0.056 & $\mathbf{A}_{2}$ & 302.18 & 8.57 \\
\hline
\end{tabular}

\section{Conclusions}

An on-surface amorphous-to-cocrystalline transformation has been demonstrated using the consecutive solvent-free deposition oftetrahedral polypyridyl molecules and a fluorinated haloarene. Raman spectroscopic studies point to the evolution of $X B$ interactions during the on-surface cocrystallization. We have shown here that the spectroscopic signature of this interaction can be tracked during this process. Moreover, the amorphous-to-crystalline transformation is not solely due to XB interactions. In situ microscopic studies of onsurface transformation suggest that the process begins with thermally-induced motion and rearrangement of the tetrahedral polypyridyl molecules on the surface. This motion and rearrangement allows the penetration of the fluorinated haloarene from the gas phase into the amorphous organic film. In situ Raman spectroscopy measurements showed that the diffusion process relies on physicochemical interactions 
between the haloarene and the organic film and involves a halogen-bonded amorphous metastable phase. Subsequently, a transformation occurs resulting in the crystalline coating. The overall process was found to be influenced by the reactivity and permeability of the amorphous films. The reactivity and permeability of the film are strongly affected by the molecular packing and influence both the absorption and the diffusion of the haloarene into the film. Nanomechanical measurements clarified the importance of the intermolecular interactions between the tetrahedral polypyridyl molecules in the amorphous phase on the transformation process. Molecular packing, which probably includes intermolecular interactions that involve the pyridine and the phenyl rings, can stiffen the amorphous film, making it less prone to rearrangement upon heating. Interestingly, the rigidity of the film affects the diffusion of the haloarene into $\mathbf{S}_{-} \mathbf{A}_{\mathbf{2}}$ from the vapor phase, resulting in formation of smaller crystallites compared to those formed on $\mathbf{S}_{\mathbf{A}} \mathbf{A}_{\mathbf{1}}$. The on-surface XB-based cocrystalline assembly $\mathbf{S}_{\mathbf{A}} \mathbf{A}_{\mathbf{1}} \cdot \mathbf{D}$ appears to be a polymorph of the corresponding $\mathbf{A}_{\mathbf{1}} \cdot \mathbf{D}$ cocrystals grown from solution. The onsurface cocrystal acquires a non-centrosymmetric crystal structure exhibiting second-order non-linear optical properties. These cocrystals are grown under conditions favoring thermodynamic stability, however, in an open system where the vapor pressure of haloarene above the crystal is reduced, they spontaneously transform to an amorphous phase with loss of haloarene over time.

\section{Conflicts of interest}

There are no conflicts to declare.

\section{Acknowledgements}

We thank Asher Auerbach and Alex Jahanfard for designing and building the cell for in situ optical microscopy and Raman spectroscopy measurements. We thank Dr. Liat Avram-Biton, Dr. Vyacheslav Kalchenko and Katya Rechav for carrying out NMR, SHG and FIB measurements, respectively. TEG is grateful to German Research Foundation (DFG) project CRC 1279 for the financial support. I.P. is the incumbent of the Sharon Zuckerman Research Fellow Chair. MvdB is the incumbent of The Bruce A. Pearlman Professorial Chair.

Notes and references

1 D. Fichou, J. Mater. Chem., 2000, 10, 571-588.

2 V. Stavila, A. A. Talin and M. D. Allendorf, Chem. Soc. Rev., 2014, 43, 5994-6010.

3 A. A. Virkar, S. Mannsfeld, Z. Bao and N. Stingelin, Adv. Mater., 2010, 22, 3857-3875.

4 S. M. McAfee, A. Payne, A. D. Hendsbee, S. Xu, Y. Zou and G. C. Welch, Sol. RRL, 2018, 2, 1800143.

5 H. Uchida, R. Yamazaki, K. Oota, K. Okimura, T. Minami, K. Takeya and K. Kawase, Cryst. Growth Des., 2018, 18, 40294036.

S. H. Yu, J. Cho, K. M. Sim, J. U. Ha and D. S. Chung, ACS
Appl. Mater. Interfaces, 2016, 8, 6570-6576.

N. J. Thompson, A. C. Jandl, J. W. Spalenka and P. G. Evans, J. Cryst. Growth, 2011, 327, 258-261.

M. Boterashvili, M. Lahav, S. Shankar, A. Facchetti and M. E. van der Boom, J. Am. Chem. Soc., 2014, 136, 11926-9. A. Y. Brewer, M. Sacchi, J. E. Parker, C. L. Truscott, S. J. Jenkins and S. M. Clarke, Phys. Chem. Chem. Phys., 2014, 16, 19608-19617.

H. A. Becerril, M. E. Roberts, Z. Liu, J. Locklin and Z. Bao, Adv. Mater., 2008, 20, 2588-2594.

K. C. Dickey, J. E. Anthony and Y. L. Loo, Adv. Mater., 2006, 18, 1721-1726.

C. B. Aakeröy, J. Desper, M. Fasulo, I. Hussain, B. Levin and N. Schultheiss, CrystEngComm, 2008, 10, 1816-1821.

A. Karagianni, M. Malamatari and K. Kachrimanis, Pharmaceutics, 2018, 10, 1-30.

W. Zhu, R. Zheng, X. Fu, H. Fu, Q. Shi, Y. Zhen, H. Dong and W. Hu, Angew. Chemie Int. Ed., 2015, 54, 6785-6789.

L. Sun, Y. Wang, F. Yang, X. Zhang and W. Hu, Adv. Mater., 2019, 31, 1902328.

J. C. Christopherson, F. Topić, C. J. Barrett and T. Friščić, Cryst. Growth Des., 2018, 18, 1245-1259.

T. Shirman, D. Freeman, Y. D. Posner, I. Feldman, A.

Facchetti and M. E. van der Boom, J. Am. Chem. Soc., 2008, 130, 8162-8163.

J. J. Colin, Ann. Chem., 1814, 91, 252-272.

B. S. G. and G. M. J. Schmidt, Tetrahedron Lett., 1970, 11, 4249-4252.

G. R. Desiraju, P. S. Ho, L. Kloo, A. C. Legon, R. Marquardt, P. Metrangolo, P. Politzer, G. Resnati and K. Rissanen, Pure Appl. Chem., 2013, 85, 1711-1713.

S. K. and J. M. L. Martin, J. Chem. Theory Comput., 2013, 9, 1918-1931.

L. P. Wolters, P. Schyman, M. J. Pavan, W. L. Jorgensen, M. F. Bickelhaupt and S. Kozuch, Comput. Mol. Sci., 2014, 4, 523-540.

P. P. and J. S. Murray, ChemPhysChem, 2013, 14, 278-294. P. Politzer, J. S. Murray and T. Clark, Phys. Chem. Chem. Phys., 2013, 15, 11178-89.

P. Politzer, J. S. Murray and T. Clark, Phys. Chem. Chem. Phys., 2010, 12, 7748-7757.

A. C. Legon, Phys. Chem. Chem. Phys., 2010, 12, $7736-$ 7747.

P. Metrangolo and G. Resnati, Science, 2008, 321, 918-919. P. M. J. Szell, S. A. Gabriel, E. Caron-Poulin, O. Jeannin, M. Fourmigué and D. L. Bryce, Cryst. Growth Des., 2018, 18, 6227-6238.

D. Cinčić, T. Friščić and W. Jones, J. Am. Chem. Soc., 2008, 130, 7524-7525.

P. Metrangolo, F. Meyer, T. Pilati, D. M. Proserpio and G. Resnati, Chem. Eur. J, 2007, 13, 5765-5772.

P. Metrangolo, H. Neukirch, T. Pilati and G. Resnati, Acc. Chem. Res., 2005, 38, 386-395.

A. Priimagi, G. Cavallo, P. Metrangolo and G. Resnati, Acc. Chem. Res., 2013, 46, 2686-2695.

E. Cariati, A. Forni, S. Biella, P. Metrangolo, F. Meyer, G. Resnati, S. Righetto, E. Tordin and R. Ugo, Chem. Commun., 
2007, 0, 2590-2592.

R. Liantonio, P. Metrangolo, T. Pilati, G. Resnati and A. Stevenazzi, Cryst. Growth Des., 2003, 3, 799-803. L. Catalano, S. PérezEstrada, G. Terraneo, T. Pilati, G. Resnati, P. Metrangolo and M. A. Garcia-Garibay, J. Am. Chem. Soc., 2015, 137, 15386-15389. F. Meyer and P. Dubois, CrystEngComm, 2013, 15, 30583071. A. Mukherjee, S. Tothadi and G. R. Desiraju, Acc. Chem. Res., 2014, 47, 2514-2524.

M. Saccone and L. Catalano, J. Phys. Chem. B, 2019, 92819290.

G. R. and G. T. A. Priimagi, G. Cavallo, A. Forni, M. Gorynsztejn-Leben, M. Kaivola, P. Metrangolo, R. Milani, A. Shishido, T. Pilati, Adv. Funct. Mater., 2012, 22, 2572-2579. P. M. and G. R. A. Priimagi, M. Saccone, G. Cavallo, A. Shishido, T. Pilati, Adv. Mater., 2012, 24, 345-352. P. M. and O. I. R. Milani, N. Houbenov, F. FernandezPalacio, G. Cavallo, A. Luzio, J. Haataja, G. Giancane, M. Saccone, A. Priimagi, CheM, 2017, 2, 417-426. M. D. H. and U. S. S. R. Tepper, S. Bode, R. Geitner, M. Jäger, H. Görls, J. Vitz, B. Dietzek, M. Schmitt, J. Popp, Angew. Chem. Int. Ed., 2017, 56, 4047-4051. P. M. and O. I. N. Houbenov, R. Milani, M. Poutanen, J. Haataja, V. Dichiarante, J. Sainio, J. Ruokolainen, G. Resnati, Nat. Commun., 2014, 5, 4043. K. H. Y. Kikkawa, M, Nagasaki, E. Koyama, S. Tsuzukia, Chem. Commun., 2019, 55, 3955-3958. L. J. W. Q. N. Zheng, X. H. Liu, T. Chen, H. J. Yan, T. Cook, D. Wang, P. J. Stang, J. Am. Chem. Soc., 2015, 1371, 96128 96131. S. Wang, W. J. Oldham, R. A. Hudack and G. C. Bazan, J. Am. Chem. Soc., 2000, 122, 5695-5709. S. Shankar, O. Chovnik, L. J. W. Shimon, M. Lahav and M. E. van der Boom, Cryst. Growth Des., 2018, 18, 1967-1977. K. E. Riley, J. S. Murray, J. Fanfrlík, J. Řezáč, R. J. Solá, M. C. Concha, F. M. Ramos and P. Politzer, J. Mol. Model., 2011, 17, 3309-3318.

C. Wang, D. Danovich, S. Shaik and Y. Mo, J. Chem. Theory Comput., 2017, 13, 1626-1637. M. . Messina, P. Metrangolo, W. Navarrini, S. Radice, G. Resnati and G. Zerbi, J. Mol. Struct., 2000, 524, 87-94. S. V. Rosokha, C. L. Stern and J. T. Ritzert, Chem. Eur. J, 2013, 19, 8774-8788.

X. Pang and W. J. Jin, New J. Chem, 2015, 39, 5477-5483. S. Y. Oh, C. W. Nickels, F. Garcia, W. Jones and T. Friščić, CrystEngComm, 2012, 14, 6110-6114.

A. Mahadevan-Jansen and C. A. Lieber, Appl. Spectrosc., 2003, 57, 1363-1367.

E. R. Berg, S. A. Freeman, D. D. Green and D. J. Ulness, J. Phys. Chem. A, 2006, 110, 13434-13446.

H. Fan, J. K. Eliason, C. D. Moliva A., J. L. Olson, S. M. Flancher, M. W. Gealy and D. J. Ulness, J. Phys. Chem. A, 2009, 113, 14052-14059.

S. S. Mirshafieyan and J. Guo, Opt. Express, 2014, 22, 31545-31554.

T. Babeva, H. Awala, M. Vasileva, J. El Fallah, K. Lazarova, S.
Thomas and S. Mintova, Dalt. Trans., 2014, 43, 8868-8876. C. Ouvrard, J. Y. Le Questel, M. Berthelot and C. Laurence, Acta Crystallogr. Sect. B Struct. Sci., 2003, 59, 512-526. F. Azzam, L. Chaunier, C. Moreau, D. Lourdin, P. Bertoncini and B. Cathala, Langmuir, 2017, 33, 4138-4145.

R. Xie, A. Karim, J. F. Douglas, C. C. Han and R. A. Weiss, Phys. Rev. Lett., 1998, 81, 1251-1254.

S. Herminghaus, K. Jacobs, K. Mecke, J. Bischof, A. Fery, M. Ibn-Elhaj and S. Schlagowski, Science, 1998, 282, 916-9. G. T. Carroll, M. E. Sojka, X. Lei, N. J. Turro and J. T. Koberstein, Langmuir, 2006, 22, 7748-7754. G. Reiter and P. G. de Gennes, Eur. Phys. J. E, 2001, 6, 2528.

S. L. Chaplot, G. J. Mclntyre, A. Mierzejewski and G. S. Pawley, Acta Cryst., 1981, B37, 2210-2214. C. R. Taylor and G. M. Day, Cryst. Growth Des., 2018, 18, 892-904.

K. Lisac, V. Nemec, F. Topić, M. Arhangelskis, P. Hindle, R. Tran, I. Huskić, A. J. Morris, T. Friščić and D. Cinčić, Cryst. Growth Des., 2018, 18, 2387-2396.

\section{Y. Shirota, J. Mater. Chem., 2000, 10, 1-25.}

A. Mukherjee, J. Teyssandier, G. Hennrich, S. De Feyter and K. S. Mali, Chem. Sci., 2017, 8, 3759-3769.

A. Kim, F. S. Ou, D. A. A. Ohlberg, M. Hu, R. S. Williams and Z. Li, J. Am. Chem. Soc., 2011, 133, 8234-8239. W. Städeli and W. von Philipsborn, Org. Magn. Reson., 1981, 15, 106-109.

C. Laurence, J. Graton, M. Berthelot and M. J. El Ghomari, Chem. - A Eur. J., 2011, 17, 10431-10444.

\section{TOC Figure}

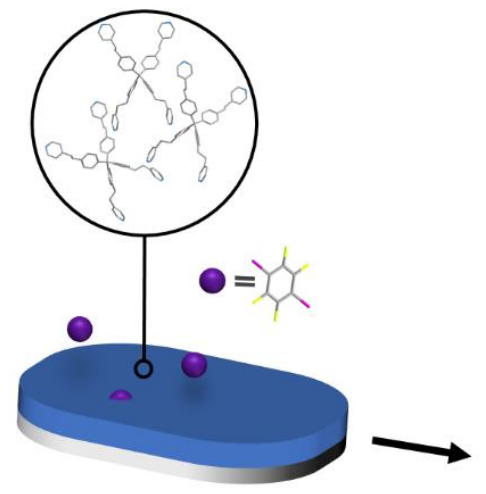

Amorphous Film

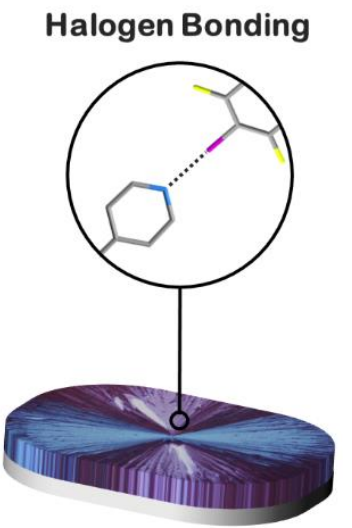

Cocrystalline Film 


\section{Electronic Supplementary Information}

\section{Halogen Bonding Caught in Action: From Amorphous-to- Cocrystalline Molecular Thin Films}

Olga Chovnik, ${ }^{\dagger}$ Sidney R. Cohen, ${ }^{\dagger}$ Iddo Pinkas, ${ }^{\ddagger}$ Lothar Houben, ${ }^{\dagger}$ Tatiana E. Gorelik,$\S$ Yishay Feldman, ${ }^{\ddagger}$ Linda J. W. Shimon, ${ }^{\ddagger}$ Mark A. Iron,${ }^{\ddagger}$ Michal Lahav, ${ }^{\dagger *}$ and Milko E. van der Boom ${ }^{\dagger *}$

$\dagger$ Department of Molecular Chemistry and Materials Science, The Weizmann Institute of Science, Rehovot 7610001, Israel.

* Department of Chemical Research Support, The Weizmann Institute of Science, Rehovot 7610001, Israel.

$\S$ Electron Microscopy Group of Materials Science, Ulm University, Ulm 89081, Germany.

milko.vanderboom@weizmann.ac.il; michal.lahav@weizmann.ac.il

\section{Methods and Materials}

\section{Nuclear Magnetic Resonance (NMR)}

${ }^{1} \mathrm{H},{ }^{13} \mathrm{C}\left\{{ }^{1} \mathrm{H}\right\}$ and ${ }^{15} \mathrm{~N}$ NMR spectra were recorded on a $11.7 \mathrm{~T}$ NMR spectrometer (Bruker, Germany). All chemical shifts $(\delta)$ are reported in ppm and coupling constants $(J)$ are in $\mathrm{Hz}$. 2D NMR experiments were performed with the following parameters: ${ }^{1} \mathrm{H}\left\{{ }^{15} \mathrm{~N}\right\} \mathrm{HMQC}$ experiments were performed using the hmqcgpqf pulse sequence. The spectra consist of a $2048 \times 256$ matrix zero-filled to $2048 \times 512$. The spectral widths were $5252 \mathrm{~Hz}\left({ }^{1} \mathrm{H}\right)$ and $10137 \mathrm{~Hz}\left({ }^{15} \mathrm{~N}\right)$. The spectra were acquired with 8 scans resulting in experiment time of 62 minutes. All measurements were carried out at $298 \mathrm{~K}$ and are referenced to the solvent shift. 


\section{UV-Vis spectroscopy}

UV-Vis spectra were recorded using Varian Cary 100 spectrophotometers in double beam transmission mode.

\section{High Resolution Mass Spectrometry (MS)}

High resolution field desorption mass spectrometry (FD-MS) measurements were performed using a Waters Micromass GCT Premier mass spectrometer (Waters Micromass, US) operating in FD mode, while electrospray ionization mass spectrometry measurements (ESI-MS) were recorded on a Micromass Platform LCZ-4000 instrument.

\section{High-performance Liquid Chromatography (HPLC)}

Analytical reversed-phase high-performance liquid chromatography (RP-HPLC) data was obtained on an Agilent Technologies 1260 Infinity HPLC (equipped with diode array UV detector and autosampler) using a C18 column. Standard RP-HPLC conditions were: mobile phase $\mathrm{A}=\mathrm{H}_{2} \mathrm{O}$, mobile phase $\mathrm{B}=\mathrm{CH}_{3} \mathrm{CN}$.

\section{Thermogravimetric Analysis (TGA) and Differential Scanning Calorimetry (DSC)}

TGA measurements were performed on a SDT Q600 Thermal Gravimetric Analyzer (TA Instruments, US) under $\mathrm{N}_{2}$ atmosphere with a heating rate of $10{ }^{\circ} \mathrm{C} / \mathrm{min}$. DSC heat-coolheat measurements were conducted using DSC Q200 (TA Instruments, US) under $\mathrm{N}_{2}$ atmosphere with a heating rate of $10^{\circ} \mathrm{C} / \mathrm{min}$ and a cooling rate of $5^{\circ} \mathrm{C} / \mathrm{min}$.

\section{Elemental Analysis}

Elemental analysis was performed by H. Kolbe, Mikroanalytisches laboratorium, Mülheim an der Ruhr, Germany.

\section{X-ray Diffraction (XRD)}

XRD patterns for phase identification were obtained on TTRAX III (Rigaku, Japan) thetatheta diffractometer equipped with a rotating $\mathrm{Cu}$ anode operating at $50 \mathrm{kV}$ and $200 \mathrm{~mA}$ and a scintillation detector. The measurements of the organic films were carried out in two reflection modes. First, an asymmetric $2 \theta$ scan with a fixed incident angle of 1 degree was 
performed using Parallel Beam optics formed by a multilayered mirror (CBO attachment). It should be pointed that the small incident angle enhances the diffraction intensity from a thin film with respect to the substrate. A polycrystalline nature of the studied films without any preferred orientation of crystallites is revealed since the direction of the observed lattice plane varies depending on the $2 \theta$ position. Then, a specular diffraction $(\theta / 2 \theta$ scan) that probes only crystallographic planes parallel to the plane of the silicon wafer was made in Bragg-Brentano geometry. Comparison of the patterns allows us to exclude the substrate peaks from Si single crystal. Powder XRD patterns were obtained either on TTRAX III, or on Ultima III (Rigaku) $\theta-\theta$ diffractometer equipped with a sealed $\mathrm{Cu}$ anode $\mathrm{X}$-ray tube operating at $40 \mathrm{kV}$ and $40 \mathrm{~mA}$ and with a scintillation counter. The measurements of the studied powders were carried out in Bragg-Brentano mode $(\theta / 2 \theta$ scan) at specular conditions. Peak positions and simulated patterns were determined using the Jade 9.5 software (Materials Data, US).

\section{Micro-Raman Spectroscopy}

Raman measurements were conducted on a LabRAM HR Evolution instrument (Horiba, France). The instrument is equipped with an $800 \mathrm{~mm}$ spectrograph allowing for high spectral resolution and low stray light. The system's pixel spacing is $1.3 \mathrm{~cm}^{-1}$ when working with a 600 groove $/ \mathrm{mm}$ grating at $632.8 \mathrm{~nm}$ excitation. The sample is exposed to light by various objectives (MPlanFL N NA-0.9, 100×, and LMPlanFL N NA-0.5 50× LWD, Olympus, Japan). The LabRAM instrument is equipped with a CCD detector: a 1024 $\times 256$ pixel open electrode front illuminated CCD camera cooled to $-60{ }^{\circ} \mathrm{C}$. The system is set around an open confocal microscope (BX-FM Olympus, Japan) with spatial resolution better than $1 \mu \mathrm{m}$ using the $100 \times$ objective. The sample is placed upon a motorized stage. The measurements were performed using a $632.8 \mathrm{~nm}$ HeNe laser with a 600 groove $/ \mathrm{mm}$ grating and a $50 \times$ or $100 \times$ objective. The Raman spectra of films grown on quartz are presented after subtraction of the background (using polynomial fitting). The peak positions were determined by Gaussian fitting of the spectra. ${ }^{\mathrm{S} 1}$ 


\section{Optical Microscopy}

Optical microscopy and polarized optical microscopy images were obtained using a Nikon Eclipse E600WPOL microscope (Nikon, Japan) equipped with a Nikon Digital Sight DSFi1-U2 camera using either reflection, transmission, or polarization mode.

\section{Surface Morphology and Nanomechanical Measurements by Atomic Force Microscopy (AFM)}

AFM studies were conducted at room temperature on a MultiMode atomic force microscope (Bruker AXS, Santa Barbara, CA) with Nanoscope V electronics and software. Topographic images of the modified silicon substrates were recorded in torsional resonance mode using AC240 AFM probes (Olympus) with a resonant frequency of $50-90 \mathrm{kHz}$ and a nominal spring constant of $0.6-3.5 \mathrm{~N} / \mathrm{m}$. The root mean square roughness values, $S_{q}$, were obtained from $1.5 \mu \mathrm{m} \times 1.5 \mu \mathrm{m}$ images. Young's moduli and adhesion measurements were collected using an ACT B-50 high density carbon ball probe $40-60 \mathrm{~nm}$ in diameter (AppNano) with a resonant frequency of $300 \mathrm{kHz}$ and a nominal spring constant of $37 \mathrm{~N} / \mathrm{m}$. The deflection sensitivity was determined from force versus distance curves on a clean sapphire sample. The spring constant of the cantilever was estimated using the thermal tune method as $30 \mathrm{~N} / \mathrm{m}$. The applied force for the nanomechanical measurements was about 300 $\mathrm{nN}$. The Young's modulus deduced from the $\mathrm{QNM}^{\mathrm{TM}}$ (quantitative nanoscale mechanical characterization) module using the DMT model for a spherical indenter. ${ }^{\mathrm{S} 2}$ For each sample, two different locations were chosen, and areas of $2 \mu \mathrm{m} \times 2 \mu \mathrm{m}$ were scanned at a pixel resolution of $256 \times 256$ so that the data reported is an average of 130,000 measurements. Gwyddion data analysis software was used for image processing. ${ }^{\mathrm{S3}}$

\section{Transmission Electron Microscopy (TEM)}

TEM imaging and electron diffraction (ED) tilt series were acquired with a Technai T12 at $120 \mathrm{kV}(\lambda=0.0335 \AA)$ and recorded on a Gatan OneView camera. The ED tilt series were collected in a continuous rotation mode around one tilt axis over a tilt range of $106^{\circ}$ in $30.24 \mathrm{~s}$ with a frame time of $159 \mathrm{~ms}$ corresponding to an angular interval of $0.56^{\circ}$. The holder used was an Ultrawin double-tilt holder, and image shift deflector coil corrections 
were applied to compensate for stage displacements during tilt. The data was processed using RDT processing software (Analytex, Sweden).

\section{Focused Ion-Beam (FIB) Assisted Preparation of Cross-Sections}

A Helios $600 \mathrm{FIB} / \mathrm{SEM}$ dual beam microscope was used for acquiring cross sections of the organic films and for their subsequent imaging. The sample was first coated with a thin layer $(\sim 10 \mathrm{~nm})$ of amorphous carbon to avoid charging of the sample surface. A protective platinum layer was then deposited locally on the area of interest before cutting.

\section{Second Harmonic Generation measurement (SHG)}

SHG measurement was performed using LSM 880 upright system (Zeiss, Germany) with non-linear optics, coupled with a Chameleon MPX (Coherent, Inc., CA, USA) femtosecond pulsed, tunable Ti:sapphire laser for two-photon excitation. Analyses were performed using ZEN Imaging software from Zeiss.

\section{Computational details}

All calculations were performed using Gaussian09 Revision E.01. ${ }^{\mathrm{S} 4}$ Geometries were optimized using the Perdew-Burke-Ernzerhof (PBE) exchange-correlation functional ${ }^{\mathrm{S} 5}$ with an empirical dispersion correction ${ }^{\mathrm{S} 6}$ added, specifically the third version of Grimme's dispersion $^{\text {S6a, S7 }}$ with Becke-Johnson dampening ${ }^{\text {S7-S8 }}$ (D3BJ); this combination is denoted as $\mathrm{PBE}_{\mathrm{D} 3 \mathrm{~B} J}$. The use of a dispersion correction is essential to properly describe a system where the interactions between the two fragments are best described as "dispersion". S9 With this functional the second revision (def2) of Ahlrichs and coworkers' basis sets ${ }^{\mathrm{S} 10}$ (def2-SVP) ${ }^{\text {S11 }}$ was used. When using a GGA functional, density fitting basis sets, specifically the fitting sets generated using the automatic generation algorithm implemented in Gaussian09, were used in order to speed up the calculations. ${ }^{\text {S12 }}$ Partial atomic charges were obtained using an iterative Hirshfeld (Hershfeld-I). ${ }^{\text {S13 }}$ Electrostatic potentials (ESP) and total electron densities were calculated using GaussView (09). Mapped surfaces were prepared with GaussView. 


\section{Chemicals and Synthesis}

2,3,5,6-Tetrafluoro-1,4-diiodobenzene (1; 97\%; Apollo Scientific Ltd.) and solvents were used as received. Tetrakis(4-pyridylethen-2-yl)tetraphenylmethane (A2) was prepared according to a literature procedure. ${ }^{\mathrm{S} 14}$

\section{Synthesis of 4,4',4", 4"'-Tetrakis(4-pyridylethyl-2-yl)tetraphenylmethane (A1).}

A mixture of 4,4',4",4"'-tetrakis(4-pyridylethen-2-yl)tetraphenylmethane (A2) $(610 \mathrm{mg}$, $0.83 \mathrm{mmol})$ and 10\% Pd/C (61 mg, $10 \mathrm{wt} \%$ of $\mathbf{A} 2)$ in MeOH:EtOAc (50\% (v/v), $15 \mathrm{~mL})$ was vigorously stirred at $30^{\circ} \mathrm{C}$ under 5 bar of $\mathrm{H}_{2}$ for $48 \mathrm{~h}$. The reaction mixture was filtered through Celite, and the filtrate was concentrated in vacuo. The residue was purified by flash column chromatography ( silica gel, $1 \%$ (v/v) EtOH in $\mathrm{CH}_{2} \mathrm{Cl}_{2}$ ) to provide compound $\mathbf{A}_{1}$ (480 mg, 80\%) as a white powder. ${ }^{1} \mathrm{H} \mathrm{NMR}\left(\mathrm{CDCl}_{3}, 500 \mathrm{MHz}\right): \delta 8.47(\mathrm{~d}, J=6.0 \mathrm{~Hz}, 8 \mathrm{H})$, $7.03(\mathrm{~m}, 24 \mathrm{H}), 2.91(\mathrm{~s}, 16 \mathrm{H}) .{ }^{13} \mathrm{C}\left\{{ }^{1} \mathrm{H}\right\} \mathrm{NMR}\left(\mathrm{CDCl}_{3}, 125 \mathrm{MHz}\right): \delta 150.6,149.8,145.0$, $138.4,131.2,127.6,124.1,63.9,37.0,36.2 \mathrm{mp} 130{ }^{\circ} \mathrm{C}$. UV/Vis $(\varepsilon)\left(n\right.$-butanol) $\lambda_{\max }=213$ $\mathrm{nm}, \varepsilon=7.1 \times 10^{5} \mathrm{~cm}^{-1} \mathrm{M}^{-1}$. HRMS $\left(\mathrm{ESI}^{+}\right) \mathrm{m} / z$ : calcd. for $\mathrm{C}_{53} \mathrm{H}_{48} \mathrm{~N}_{4} 741.3958$, found 741.3969. Anal. calcd. for $\mathrm{C}_{53} \mathrm{H}_{48} \mathrm{~N}_{4}+2\left(\mathrm{H}_{2} \mathrm{O}\right): \mathrm{C}, 81.92 ; \mathrm{H}, 6.75 ; \mathrm{N}, 7.21 ; \mathrm{O}, 4.12$. Found C, 82.20; H, 6.25; N, 7.19.

\section{Single Crystal X-ray Analyses and Data Collection Parameters.}

Preparation of crystal A 1 . Compound $\mathbf{A}_{1}$ (7.0 mg, $\left.9.4 \mathrm{mmol}\right)$ was dissolved in chloroform $(150 \mu \mathrm{L})$, and hexane $(1.5 \mathrm{~mL})$ was then gently added. The vial was loosely sealed to allow slow solvent evaporation at room temperature. X-ray quality crystals were obtained after 2 days.

$\mathrm{C}_{53} \mathrm{H}_{48} \mathrm{~N}_{4}+4\left(\mathrm{H}_{2} \mathrm{O}\right)$ : colorless needle, $0.24 \mathrm{~mm} \times 0.08 \mathrm{~mm} \times 0.04 \mathrm{~mm}$, Tetragonal, space group $P 4 / n, a=b=16.9878(2) \AA, c=7.94418(7) \AA, T=100(2) \mathrm{K}, V=2292.57(7) \AA^{3}, Z$ $=2, F_{w}=1719.09, D_{c}=1.178 \mathrm{Mg} \cdot \mathrm{m}^{-3}, \mu=0.585 \mathrm{~mm}^{-1}$. Data collection and processing: Rigaku XtaLabPro diffractometer, $\mathrm{CuK} \alpha_{1}(\lambda=1.54184 \AA), 11444$ reflections collected, 2434 independent reflections $\left(R_{\text {int }}=0.0296\right) .-21 \leq h \leq 19,-20 \leq k \leq 16,-9 \leq l \leq 6$, frame scan width $=0.5^{\circ}$, scan speed $1.0^{\circ}$ per $2 \mathrm{sec}$ or $6 \mathrm{sec}$, low $\theta /$ high $\theta$ respectively, typical peak mosaicity $0.6^{\circ}$. The data were processed with RigakuOD CrysAlisPro. Solution and refinement: Structure solved by direct method with SHELXT-2014 ${ }^{\text {S15 }}$ Full matrix least- 
squares refinement based on $F^{2}$ with SHELXL-2016. ${ }^{\text {S16 }} 194$ parameters with 3 restraints, final $R_{1}=0.0444$ (based on $F^{2}$ ) for data with $I>2 \sigma(I)$ and $R_{1}=0.0480$ on 2434 reflections. Goodness of fit on $F^{2}=1.140$, largest electron density peak $=0.220 \mathrm{e} \cdot \AA^{-3}$, deepest hole $=$ $-0.281 \mathrm{e} \cdot \AA^{-3}$. Details can be obtained from the the Cambridge Crystallographic Data Centre (CCDC 1907986).

Preparation of cocrystal $A_{I} \cdot D$. Colorless plate-like crystals were obtained by solvent evaporation at room temperature. Compounds $\mathbf{A}_{\mathbf{1}}(75 \mathrm{mg}, 0.10 \mathrm{mmol})$ and $\mathbf{D}$ (160 mg, 0.39 mmol) were placed in a $10 \mathrm{~mL}$ stainless steel jar along with $50 \mu \mathrm{L}$ of chloroform and three stainless steel balls $7 \mathrm{~mm}$ in diameter. The mixture was then milled for $15 \mathrm{~min}$. in a Tehtnica Millmix 200 operating at a frequency of $25 \mathrm{~Hz}$. The grounded powder $(10 \mathrm{mg})$ was dissolved in chloroform $(1 \mathrm{~mL})$ and left for a week to crystallize.

$\mathrm{C}_{53} \mathrm{H}_{48} \mathrm{~N}_{4}+2\left(\mathrm{C}_{6} \mathrm{~F}_{4} \mathrm{I}_{2}\right)$ : colorless plate, $0.24 \mathrm{~mm} \times 0.22 \mathrm{~mm} \times 0.08 \mathrm{~mm}$, Monoclinic, space group $C 2 / c, a=35.5963(8) \AA, b=7.3398(2) \AA, c=29.9644(8) \AA, \beta=115.267(2)^{\circ}, T=$ 100(2) K, $V=7079.8(3) \AA^{3}, Z=4, F_{\mathrm{w}}=1544.67, D_{\mathrm{c}}=1.449 \mathrm{Mg} \cdot \mathrm{m}^{-3}, \mu=1.819 \mathrm{~mm}^{-1}$. Data collection and processing: Rigaku XtaLabPro diffractometer, $\operatorname{MoK} \alpha(\lambda=0.71073 \AA)$, 126176 reflections collected, 10799 independent reflections $\left(R_{\text {int }}=0.0437\right)$. $-50 \leq h \leq 47$, $10 \leq k \leq 10,-42 \leq l \leq 42$, frame scan width $=0.5^{\circ}$, scan speed $1.0^{\circ}$ per $60 \mathrm{sec}$, typical peak mosaicity $0.6^{\circ}$. The data were processed with RigakuOD CrysAlisPro. Solution and refinement: Structure solved by direct method with SHELXT-2013. ${ }^{\text {S14 }}$ Full matrix leastsquares refinement based on $\mathrm{F}^{2}$ with SHELXL-2013. ${ }^{\text {S15 }} 367$ parameters with 0 restraints, final $R_{1}=0.0672\left(\right.$ based on $F^{2}$ ) for data with $I>2 \sigma(I)$ and $R_{1}=0.0718$ on 10799 reflections. Goodness of fit on $F^{2}=1.273$, largest electron density peak $=2.817 \mathrm{e} \cdot \AA^{-3}$, deepest hole $=$ $-0.661 \mathrm{e} \cdot \AA^{-3}$. Details can be obtained from the Cambridge Crystallographic Data Centre (CCDC 1907985).

Preparation of crystal $\boldsymbol{A}_{2}$. Slow evaporation of a $\mathrm{CHCl}_{3}$ solution of acceptor $\mathbf{A}_{2}$ at room temperature resulted in the formation of colorless, needle-like crystals, suitable for single crystal X-ray diffraction analysis. ${ }^{\mathrm{S} 17}$

\section{Preparation of crystalline XB-based films (S_A1·D and $\left.S_{-} A_{2} \cdot D\right)$.}

Substrate preparation. Single-crystal silicon (100) (Wafernet) was cleaned by sequential sonication (10 min. each) in hexane, acetone, and isopropanol followed by $20 \mathrm{~min}$. of 
UV/Ozone cleaning (UVOCS). Quartz (fused, Chemglass Inc.) substrates were cleaned by immersion in a "piranha" solution ( $\left(7: 3(\mathrm{v} / \mathrm{v}) \mathrm{H}_{2} \mathrm{SO}_{4} / 30 \% \mathrm{H}_{2} \mathrm{O}_{2}\right)$ for $1 \mathrm{~h}$. Caution: piranha solution is an extremely dangerous oxidizing agent and should be handled with care using appropriate personal protection. Subsequently, the substrates were rinsed with deionized (DI) water followed by the RCA cleaning protocol: 1:5:1 (v/v) $\mathrm{NH}_{4} \mathrm{OH} / \mathrm{H}_{2} \mathrm{O} / 30 \% \mathrm{H}_{2} \mathrm{O}_{2}$ at $80{ }^{\circ} \mathrm{C}$ for $45 \mathrm{~min}$. The substrates were then washed consecutively with DI water, acetone, and iso-propanol. Both silicon (100) and quartz slides were then dried under a $\mathrm{N}_{2}$ stream. The silicon nitride membrane window TEM grids $(50 \mathrm{~nm}$ hydrophilic membrane, $0.5 \mathrm{~mm}$ $\times 0.5 \mathrm{~mm}$ window; Ted Pella, Inc.) were used as received without any prior cleaning.

Formation of $S_{-} \boldsymbol{A}_{\mathbf{1}}$ and $\boldsymbol{S}_{-} \boldsymbol{A}_{2}$. Physical vapor deposition (PVD) of compounds $\mathbf{A}_{1}$ and $\mathbf{A}_{2}$ on quartz, silicon or silicon nitride TEM substrates was carried out using a Nano 36 thin film deposition system (Kurt J. Lesker). The depositions were performed at a constant rate $\left(0.2 \AA / s, \sim 3 \times 10^{-6}\right.$ Torr) keeping the substrates at room temperature. The rate of deposition was controlled by adjusting the temperature of the crucible $\left(300-350^{\circ} \mathrm{C}\right)$. A quartz-crystal microbalance was used to monitor the deposition of the materials.

Formation of $S_{-} A_{1} \cdot D$ and $S_{-} \boldsymbol{A}_{2} \cdot \boldsymbol{D}$. The films (S_A1 or $\left.\mathbf{S} \_\mathbf{A}_{2}\right)$ were placed in a petri dish $\left(9 \mathrm{~cm}\right.$ in diameter, $\left.\mathrm{V}=95 \mathrm{~cm}^{3}\right)$ in the vicinity of compound $\mathbf{D}(150 \mathrm{mg}, 0.37 \mathrm{mmol})$. The petri dish was then covered and placed in a preheated oven at $65{ }^{\circ} \mathrm{C}$ for $12 \mathrm{~h}$, after which it was removed from the oven and allowed to cool down to room temperature before characterization.

\section{Thermal stability of $S \_A_{1} \cdot D$ and $S \_A_{2} \cdot D$.}

Films $\mathbf{S} \_\mathbf{A}_{\mathbf{1}}$ and $\mathbf{S} \_\mathbf{A} \mathbf{2}$ were placed in a petri dish $\left(9 \mathrm{~cm}\right.$ in diameter, $\left.\mathrm{V}=95 \mathrm{~cm}^{3}\right)$. The petri dish was then covered and placed in a preheated oven at $65^{\circ} \mathrm{C}$ for $12 \mathrm{~h}$, after which it was removed from the oven and allowed to cool down to room temperature before characterization.

\section{Characterization of $S_{-} \_\mathbf{A} \cdot \mathbf{D}$.}

Exposing $\mathbf{S} \_\mathbf{A}_{2}$ to vapor of $\mathbf{D}$ results in changes in surface morphology and roughness, XRD profile, as well as the Raman and UV-vis spectra (Figures S11-15). The presence of D on the surface is supported by RP-HPLC and MS analyses (Figure S16, Table S2). RPHPLC chromatogram of the redissolved $\mathbf{S} \_\mathbf{A} 2 \cdot \mathbf{D}$ shows elution of $\mathbf{A} \mathbf{2}$ and $\mathbf{D}$ consistent with 
retention times observed for $\mathbf{S} \_\mathbf{A}_{1}$ and $\mathbf{D}$, respectively. MS analysis of the redissolved S_A2 $\mathbf{D}$ confirms the presence of $\mathbf{A} 2$ and $\mathbf{D}$ showing peaks at $m / e 732.47$ (A2) and 401.86 (D). The differences in the Raman signatures and XRD profiles between $\mathbf{S}_{-} A_{2} \cdot \mathbf{D}$ and $\mathbf{A}_{2} \cdot \mathbf{D}$ suggest a different molecular arrangement of constituents on the surface (Table S1; Figure S14 and S19), as with the S_A1·D crystalline film.

\section{In situ micro-Raman spectroscopy measurements.}

S_A1 or S_A $\mathbf{A}$ and compound D (15 mg, $0.037 \mathrm{mmol})$ were placed in a Raman cell $(\mathrm{V}=$ $2.8 \mathrm{~cm}^{3}$ ) (Figure 5a). The Raman cell was then sealed and heated to $65{ }^{\circ} \mathrm{C}$ for $12 \mathrm{~h}$. The time it takes to reach $65^{\circ} \mathrm{C}$ is $\sim 3 \mathrm{~min}$. Optical and spectroscopic measurements were collected from $t=0 \mathrm{~min}$ in a sequential manner, with an interval of $\sim 1.5 \mathrm{~min}$. between each measurement $(1.5 \mathrm{~min}$. is the time it takes to focus on the features on the surface and to collect the Raman spectrum in the range of $100-1800 \mathrm{~cm}^{-1}$ ). The cell was made out of copper in order to provide good heat transfer between the heating stage and the cell body. The inner part of this cell is composed of two glass microscope slides $(25 \mathrm{~mm} \times 75 \mathrm{~mm} \times$ $1 \mathrm{~mm}$; ThermoScientific) separated by a $1 \mathrm{~mm}$ Teflon spacer. The temperature of the Raman cell was controlled and monitored by a temperature controller (Pixsys ATR 121141B) with a $1.6 \mathrm{~mm}$ diameter sampling tip thermocouple probe $\left( \pm 0.1^{\circ}\right)$.

Movie S1. Electron diffraction (ED) tilt series of S_A1・D on a TEM grid with a hydrophilic $50 \mathrm{~nm}$ silicon nitride membrane. The ED tilt series was collected over a tilt range of $106^{\circ}$.

Movie S2. Series of time-resolved optical microscopy images showing the growth of S_A1.D on a silicon substrate coated with $\mathbf{S} \_\mathbf{A} 1$ at $65{ }^{\circ} \mathrm{C}$ in the custom-made cell. The images were collected every $\sim 1.5 \mathrm{~min}$. employing a 10x objective.

Movie S3. Series of time-resolved optical microscopy images showing the changes occurring to $\mathbf{S} \_\mathbf{A} 1$ on a silicon substrate at $65{ }^{\circ} \mathrm{C}$ in a Raman cell. The images were collected every $\sim 1.5$ min. employing a 10× objective. 
a

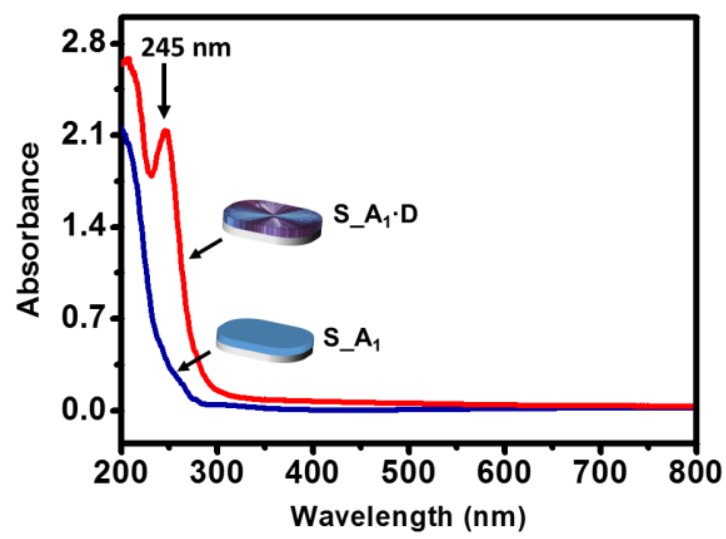

b

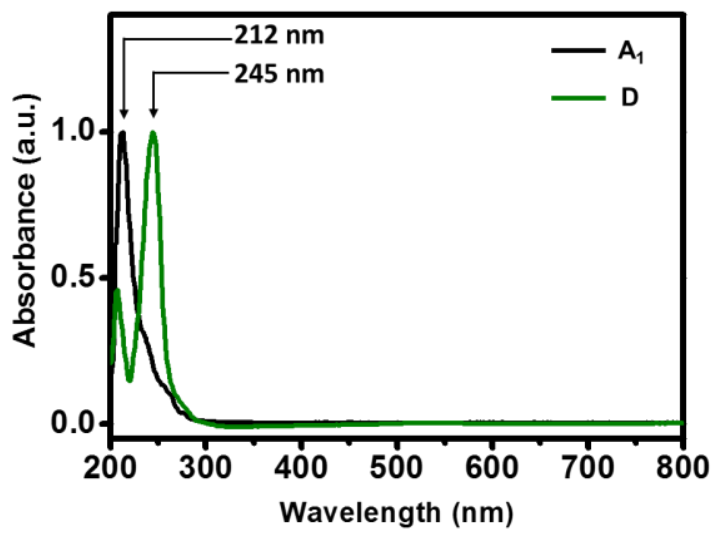

Figure S1. Absorption spectra of $\mathrm{S}_{-} \mathrm{A}_{1}$ (blue) and $\mathrm{S}_{-} \mathrm{A}_{1} \cdot \mathrm{D}$ (red) on quartz substrates (a). The spectrum of S_A $A_{1}$ has an absorbance maximum at $\lambda_{\max } \approx 209 \mathrm{~nm}$. Absorption spectra of individual components $\mathrm{A}_{1}$ (black) and $\mathrm{D}$ (green) in $n$-butanol (b).

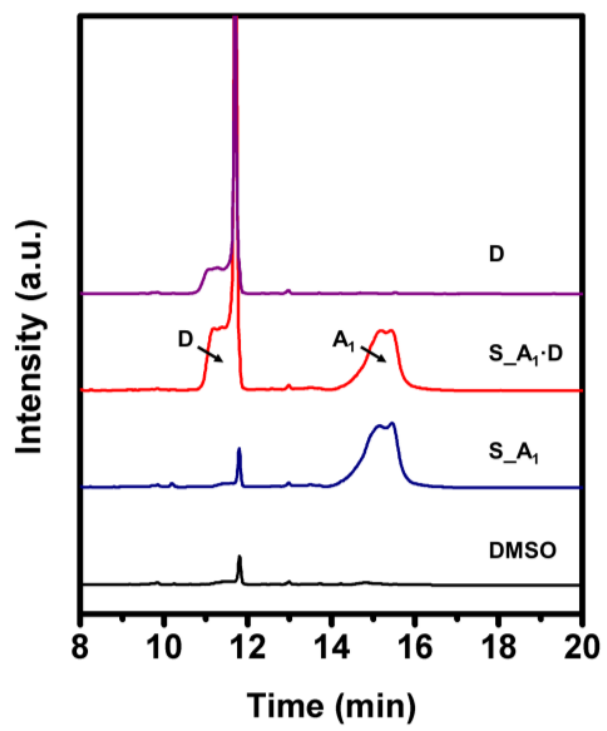

Figure S2. Reverse-phase HPLC (RP-HPLC) analysis of S_A $\mathbf{A}$ before heating (blue) and after exposure to D (red). Black and purple chromatograms are of DMSO and of $\mathbf{D}$, respectively. The chromatograms were obtained by dissolving the deposited organic materials or the powder (D) using DMSO. The ratio between the peaks areas corresponding to $\mathbf{A} \mathbf{1}$ and $\mathbf{D}$ shown in the chromatogram (red) of $\mathbf{S} \_\mathbf{A} \mathbf{1} \cdot \mathbf{D}$ is 1:1.7. 
a

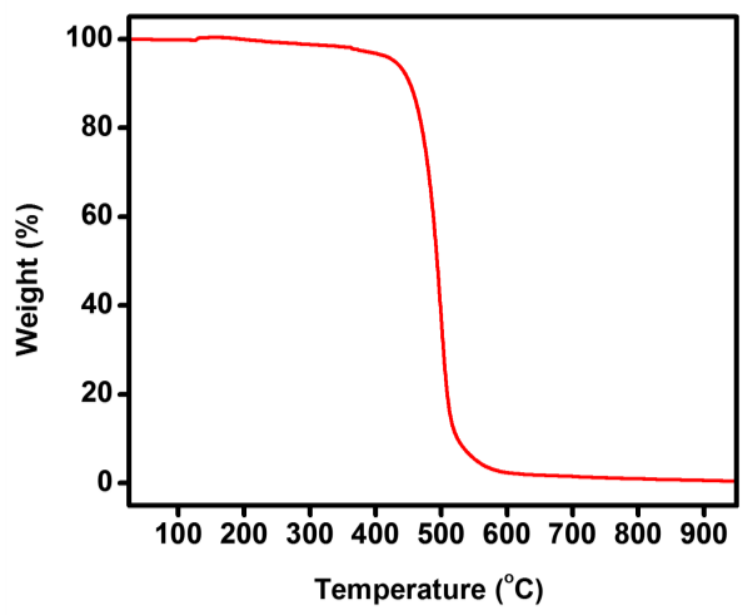

b

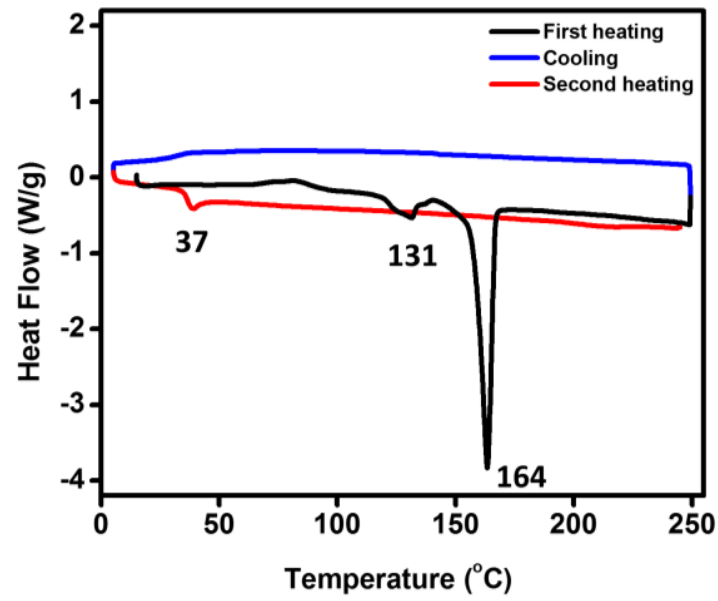

Figure S3. TGA (a) and DSC heat-cool-heat thermogram (b) of the XB acceptor A1. (a) TGA: the compound displays high thermal stability with $5 \%$ weight loss at $427^{\circ} \mathrm{C}$; (b) DSC: endothermic peaks at $131^{\circ} \mathrm{C}$ and 164 ${ }^{\circ} \mathrm{C}$ are observed upon first heating of $\mathbf{A}_{\mathbf{1}}$; no recrystallization of $\mathbf{A}_{\mathbf{1}}$ takes place during cooling; a glass transition is apparent upon second heating at $37^{\circ} \mathrm{C}$.

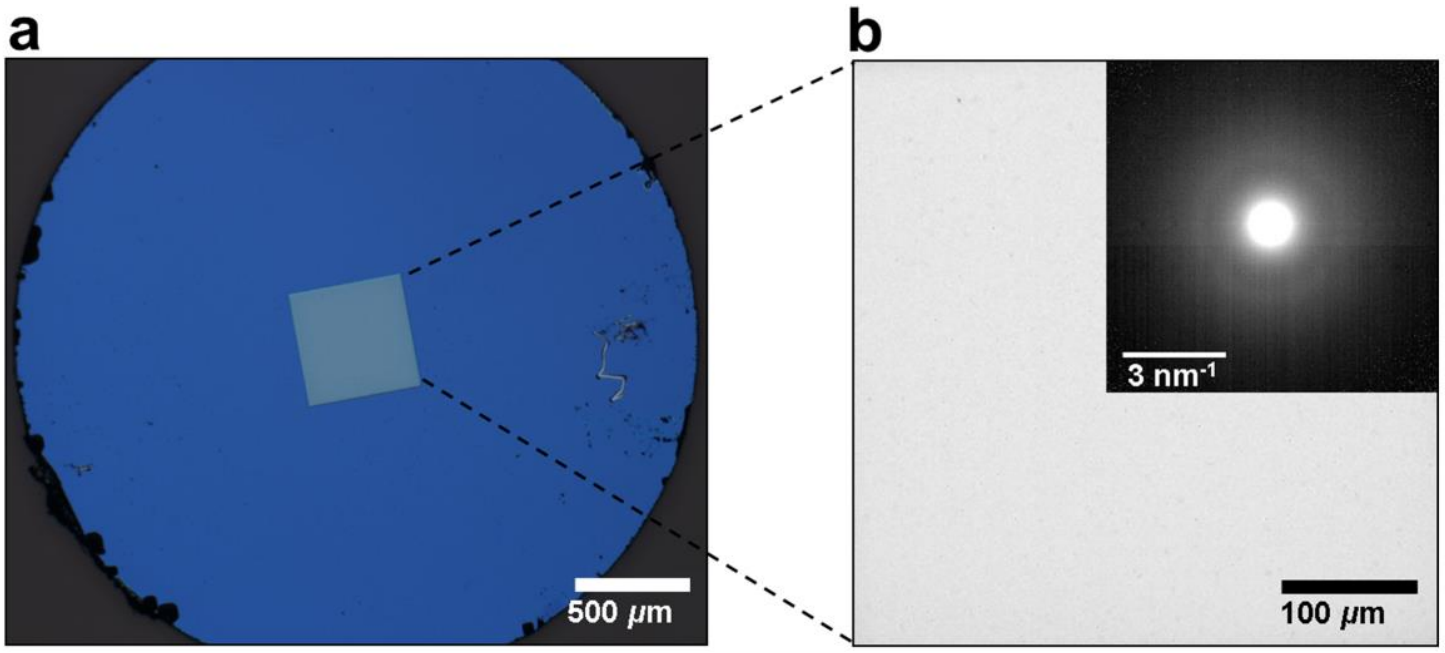

Figure S4. Optical microscopy (a) and transmission electron microscopy (TEM) (b) of $\mathbf{S} \_\mathbf{A} \mathbf{1}$ on a TEM grid with a hydrophilic $50 \mathrm{~nm}$ silicon nitride membrane $(0.5 \mathrm{~mm} \times 0.5 \mathrm{~mm}$ window). The inset shows the electron diffraction pattern of the amorphous $\mathbf{S} \_\mathbf{A}_{\mathbf{1}}$. 


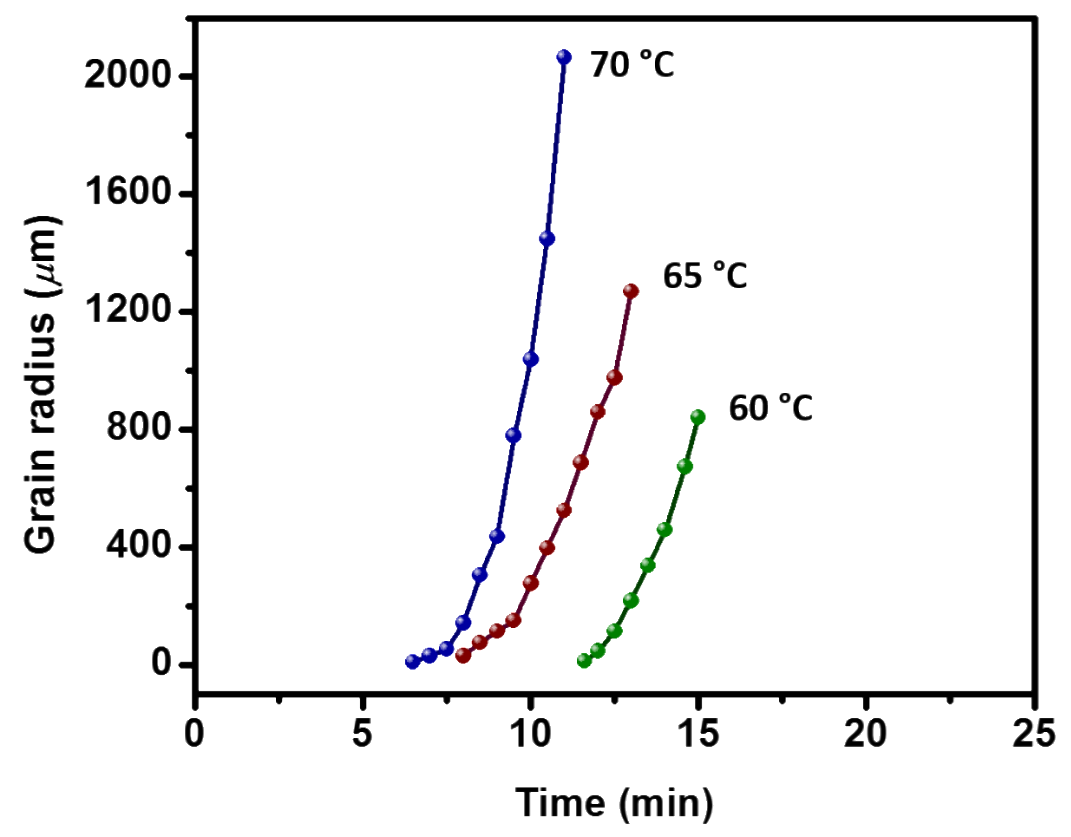

Figure S5. Crystal grain radius at different temperatures. Data taken from optical imaging (data not shown). 
a

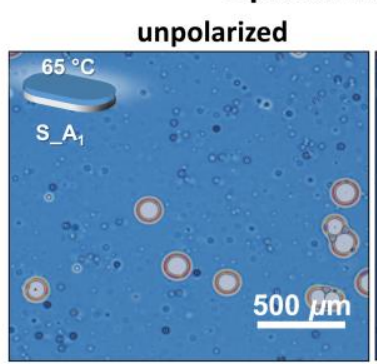

b

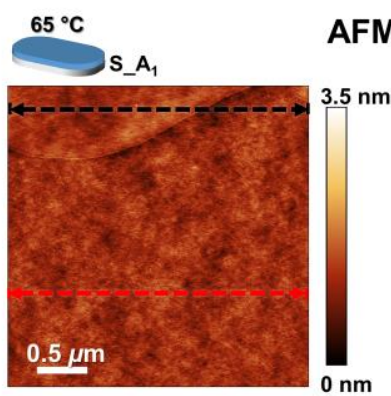

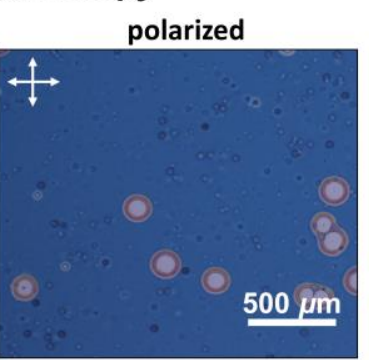

AFM

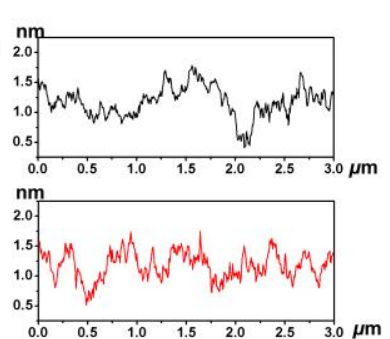

C

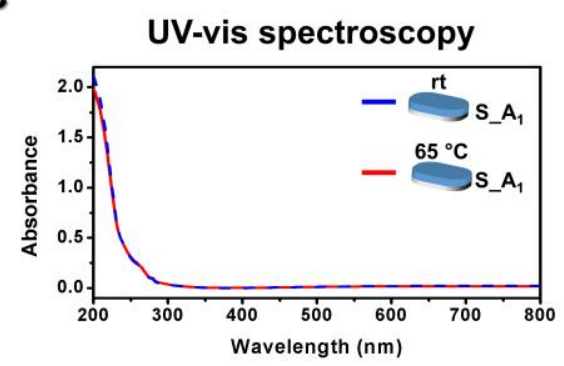

d
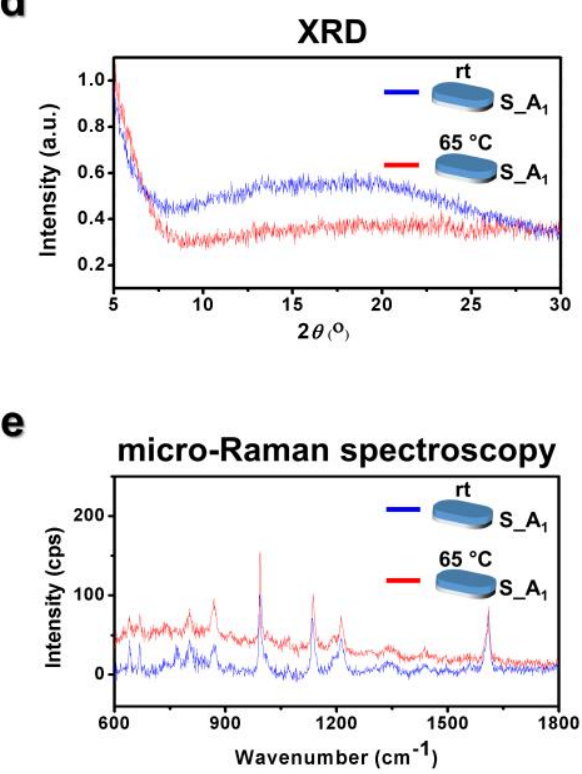

Figure S6. Characterization of thermally treated $\mathbf{S} \_\mathbf{A}_{\mathbf{1}}$ in absence of $\mathbf{D}$. $\mathbf{S} \_\mathbf{A}_{\mathbf{1}}$ which was heated in an oven at $65{ }^{\circ} \mathrm{C}$ for $12 \mathrm{~h}$. (a) Optical micrographs showing the changes in $\mathbf{S} \_\mathbf{A}_{1}$ on silicon upon heating, viewed without polarization (left) and between crossed polarizers (right) in a reflection mode. (b) AFM topography and height profile of the two indicated regions on S_A1. The topology of the amorphous region, measured along the red and black lines of the AFM image, shows only slight changes upon heating. The RMS roughness $\left(\mathrm{S}_{q}\right.$ ), measured over a $1.5 \mu \mathrm{m} \times 1.5 \mu \mathrm{m}$ area, is $\sim 0.3 \mathrm{~nm}$, corresponding to a smooth surface. (c) Absorption spectra of $\mathbf{S}_{-} \mathbf{A}_{1}$ on a quartz substrate before (blue) and after (red) heating. (d) Reflection XRD patterns of S_A1 on a $\operatorname{Si}(100)$ substrate before (blue) and after (red) heating. (e) Raman spectra (excitation at $\lambda=633$ nm, a $100 \times$ objective) of $\mathbf{S} \_\mathbf{A}_{\mathbf{1}}$ on a quartz substrate before (blue) and after (red) heating. 


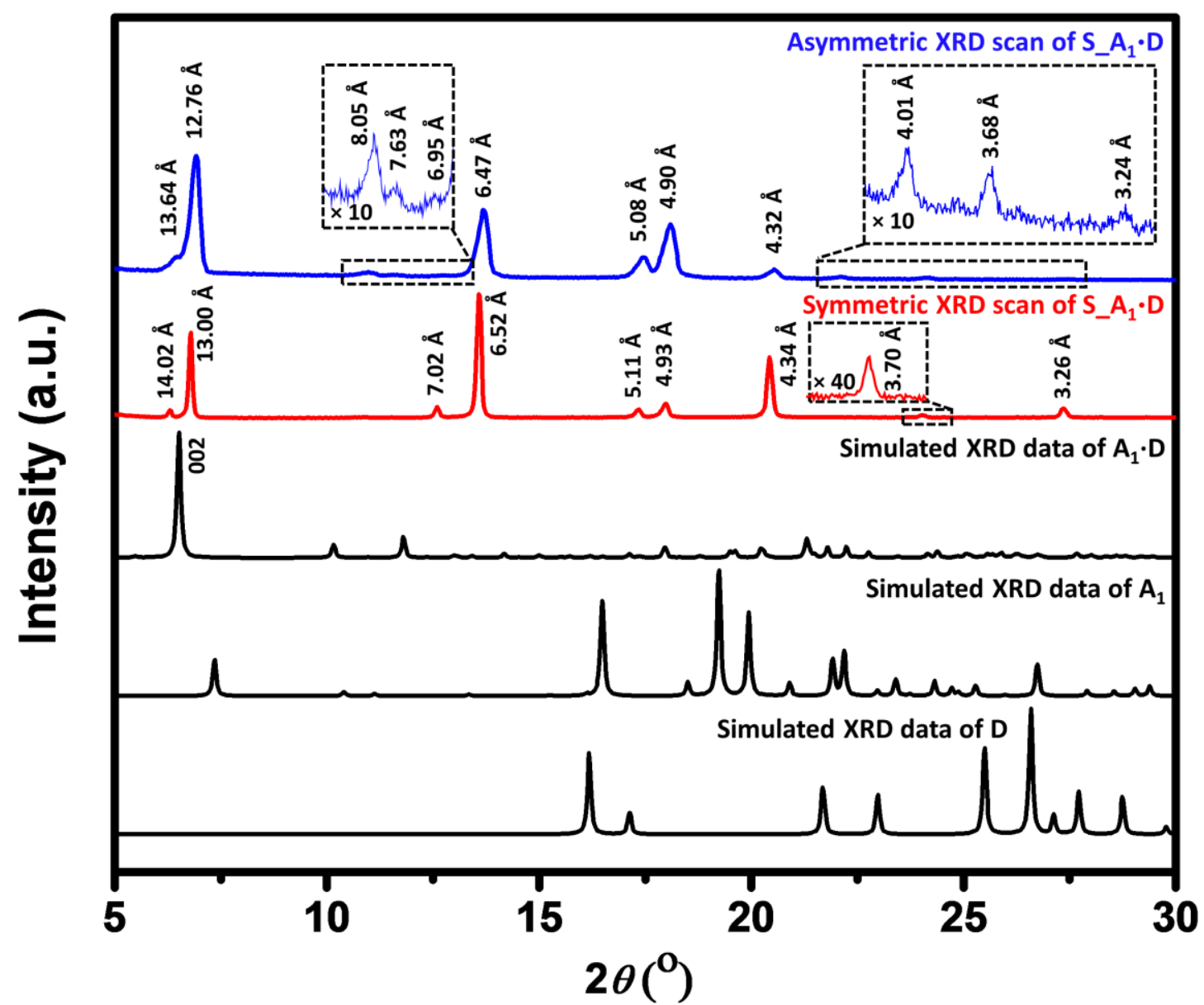

Figure S7. Reflection XRD patterns of an $\mathbf{S} \_\mathbf{A}_{\mathbf{1}} \cdot \mathbf{D}$ film on a $\mathrm{Si}(100)$ substrate measured in symmetric (red) and asymmetric (blue) modes compared with the simulated XRD patterns of $\mathbf{A}_{\mathbf{1}} \cdot \mathbf{D}, \mathbf{A}_{\mathbf{1}}$ and $\mathbf{D}$ single crystals grown from solution (black). Symmetric scan allows measuring lattice planes parallel to the sample surface, while asymmetric scan measures lattice planes inclined to the sample surface. The simulated patterns were generated using the Mercury software program (v3.9, 2017, Cambridge Crystallographic Database). 


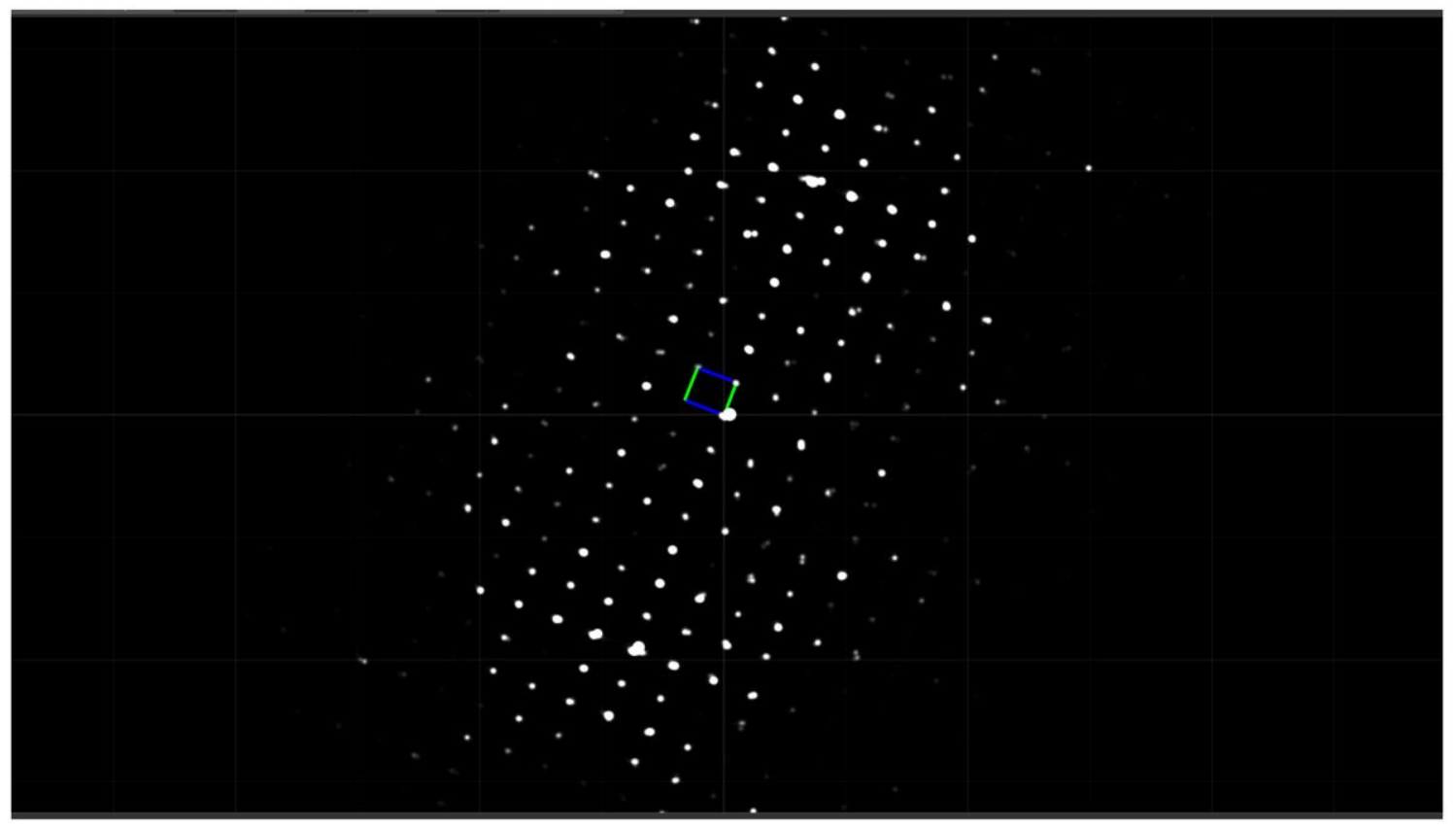

Figure S8. Reciprocal space projection of a dataset composed of ED tilt series collected on $\mathbf{S} \_\mathbf{A} \mathbf{A} \cdot \mathbf{D}$ viewed along the $a^{*}$ direction. Lines of reflections along the $c^{*}$ direction (blue vector) are missing. 


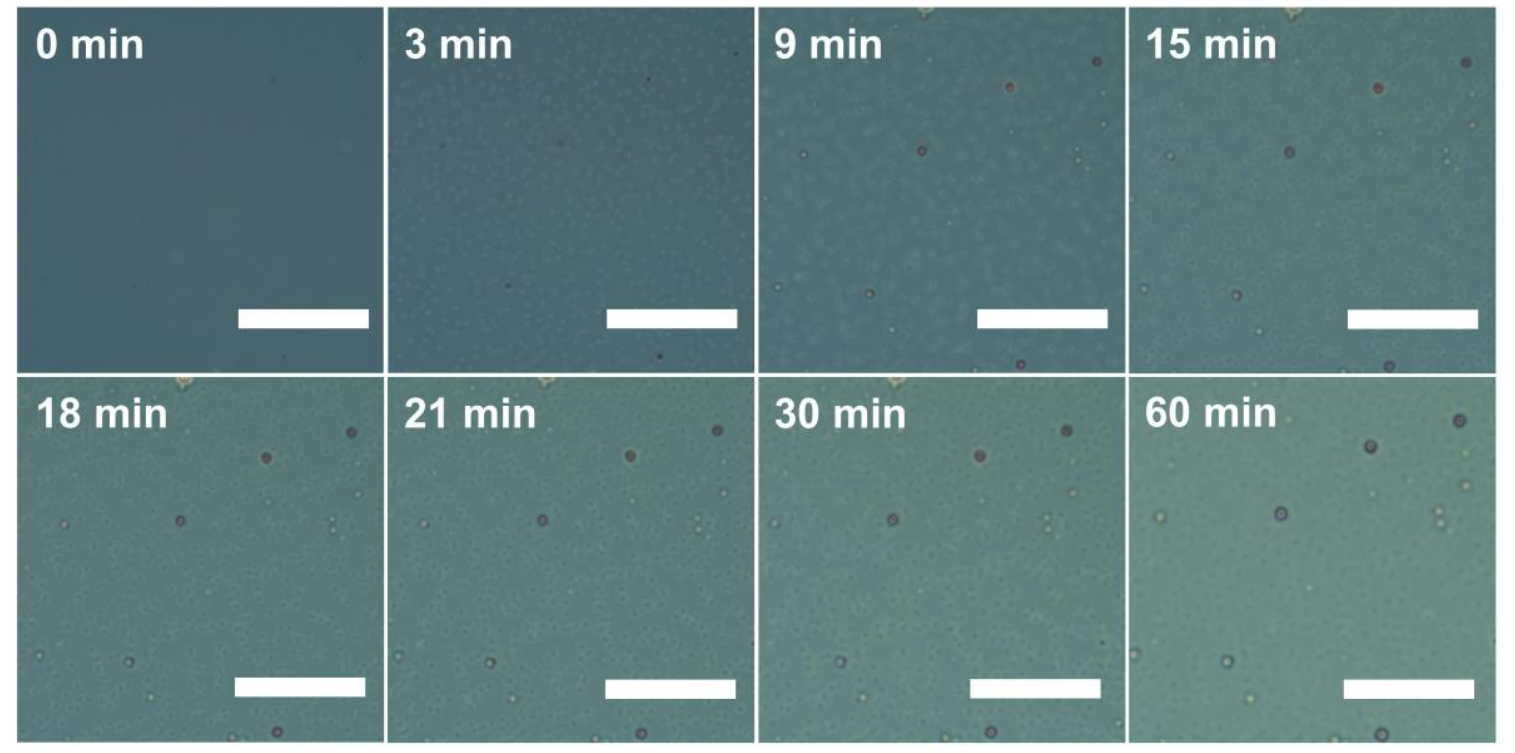

Figure S9. Optical microscopy of the changes occurring upon heating amorphous $\mathbf{S}_{-} \mathbf{A}_{1}$ on silicon at $65^{\circ} \mathbf{C}$. The process was followed for a sample placed in the custom-made hermitic cell employing a $10 \times$ objective. Time snapshots were taken from Movie S3. The scale bar is $150 \mu \mathrm{m}$. Inset: $\mathbf{S} \_\mathbf{A}_{\mathbf{1}}$ film after $720 \mathrm{~min}$. of heating; scale bar, $10 \mu \mathrm{m}$. 

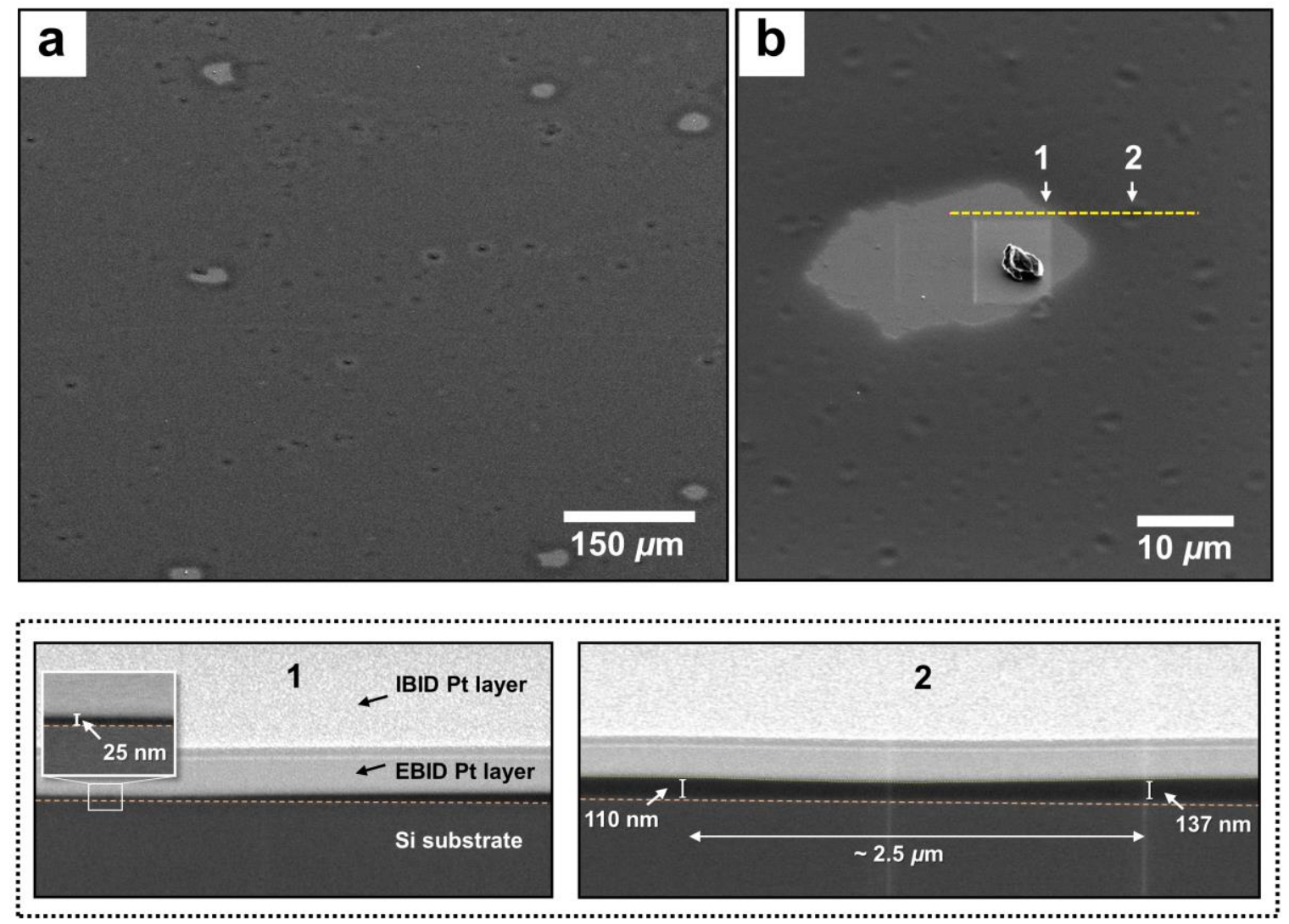

Figure S10. SEM micrographs of $\mathbf{S}_{-} \mathbf{A}_{1}$ heated at $65^{\circ} \mathrm{C}$ on a Si substrate. Cross-sections of an indicated area in (b) show the rearrangement induced on $\mathbf{S}_{-} \mathbf{A}_{\mathbf{1}}$ amorphous homogeneous film by heating, resulting in pits of varying depth on its surface. The surface was sputtered with amorphous carbon $\sim 10 \mathrm{~nm}$ thick. To protect S_A from FIB-induced damage, the region of the cross section was coated with a protective platinum layer. IBID = ion-beam induced deposition; EBID = electron-beam induced deposition. Average size distribution of the pits (two lengths perpendicular to each other): $3.9 \pm 1.3 \mu \mathrm{m} \times 5.0 \pm 2.2 \mu \mathrm{m}$. 

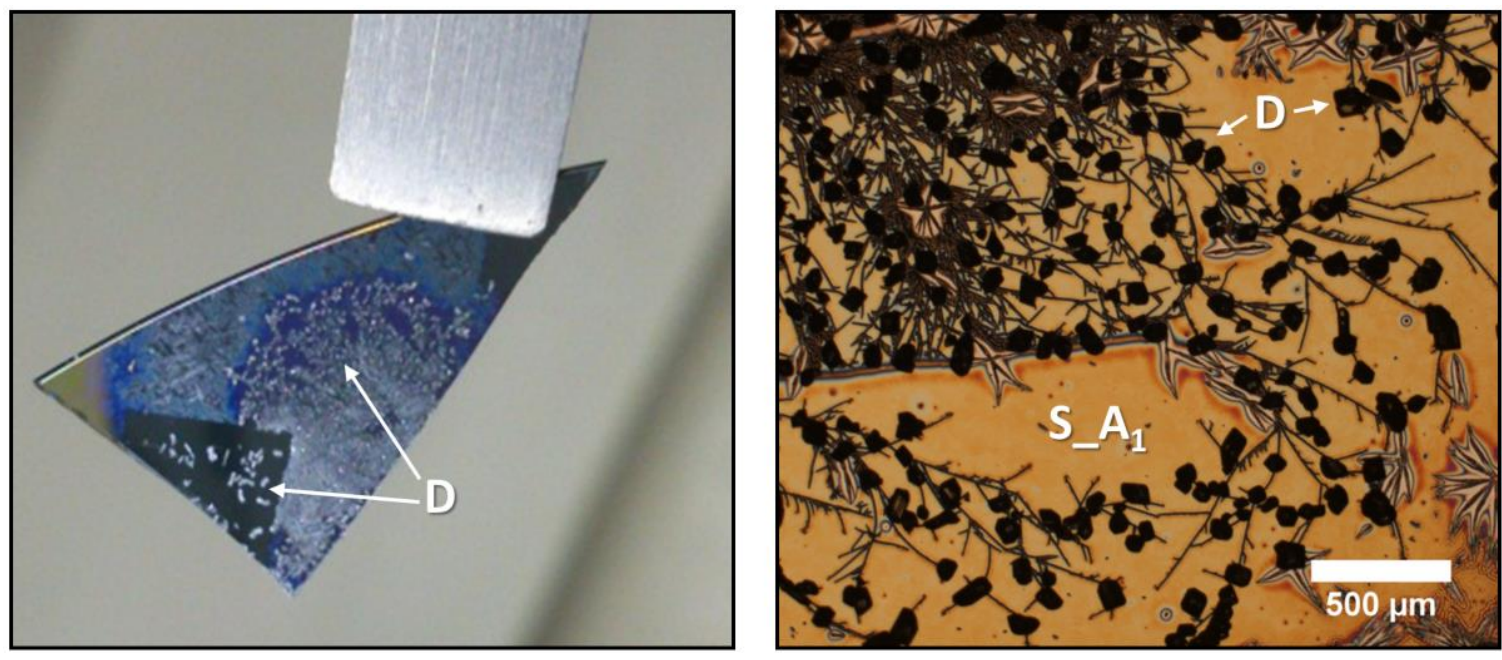

Figure S11. Photograph (left) and optical microscopy micrograph (right) of $\mathbf{S} \_\mathbf{A}_{\mathbf{1}}$ after exposure to vapors of $\mathbf{D}$ at RT. The observed 3D crystals, needles and prisms, were found to be the high temperature polymorph of $\mathbf{D}\left(P 2_{1} / \mathrm{c}: a=8.026(4), b=6.069(4), c=9.239(4), \beta=100.27^{\circ}\right)$. 
a

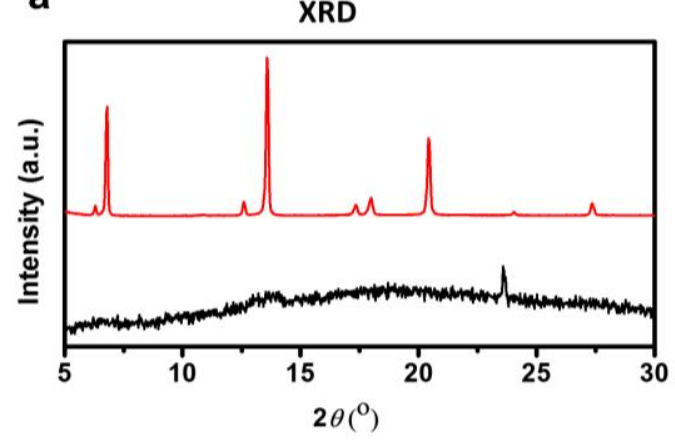

b

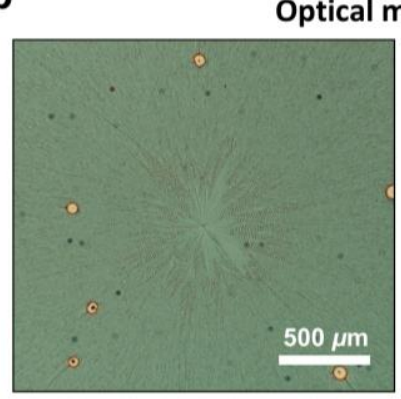

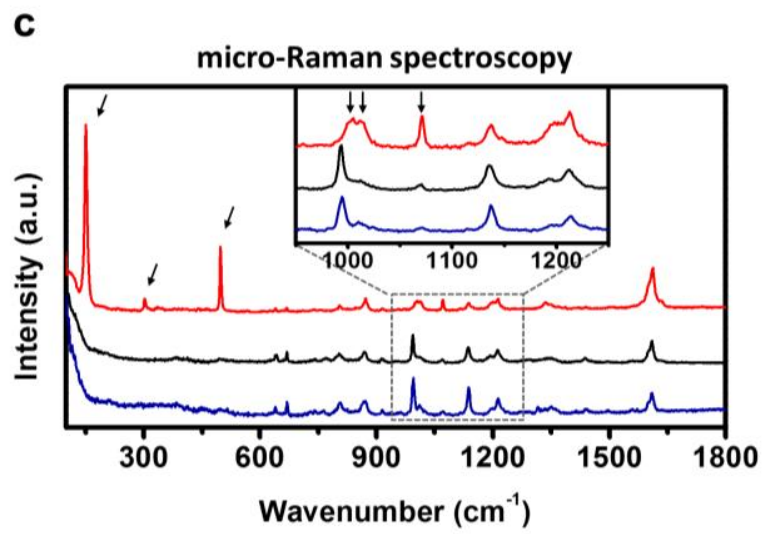

Figure S12. Stability of $\mathbf{S} \_\mathbf{A}_{1} \cdot \mathbf{D}$ as a function of temperature and time. (a-b) Reflection XRD patterns and the corresponding optical micrographs of $\mathbf{S} \_\mathbf{A}_{1} \cdot \mathbf{D}$ on a $\mathbf{S i}(100)$ substrate. (a) $\mathbf{S} \_\mathbf{A}_{1} \cdot \mathbf{D}$ (red) loses its crystallinity with time (elapsed time between the measurements is $\sim 2$ years) as indicated by the loss of sharp diffraction peaks and the appearance of an amorphous halo (black). The peak at $2 \theta=23.58^{\circ}$ (lattice spacing of $d=3.76 \AA$ ) is in the range of weak intramolecular interactions. ${ }^{\mathrm{S} 18}$ (b) The amorphization of the $\mathbf{S} \_\mathbf{A}_{\mathbf{1}} \cdot \mathbf{D}$ is accompanied by disappearance of birefringence (right, between crossed polarizers) while still retaining its macroscopic shape (left, without polarization). (c) Raman spectrum of $\mathbf{S} \_\mathbf{A}_{1} \cdot \mathbf{D}$ on a quartz substrate (red). The amorphization of the film is attributed to the loss of $\mathbf{D}$ with time (black), indicated by the disappearance of peaks corresponding to $\mathbf{D}$ and the cocrystal (black arrows) in the spectrum of a three-month aged sample. The process can be induced by heating at $100{ }^{\circ} \mathrm{C}$ for $25 \mathrm{~h}$ (blue). The Raman spectra measured with excitation at $632.8 \mathrm{~nm}$. 


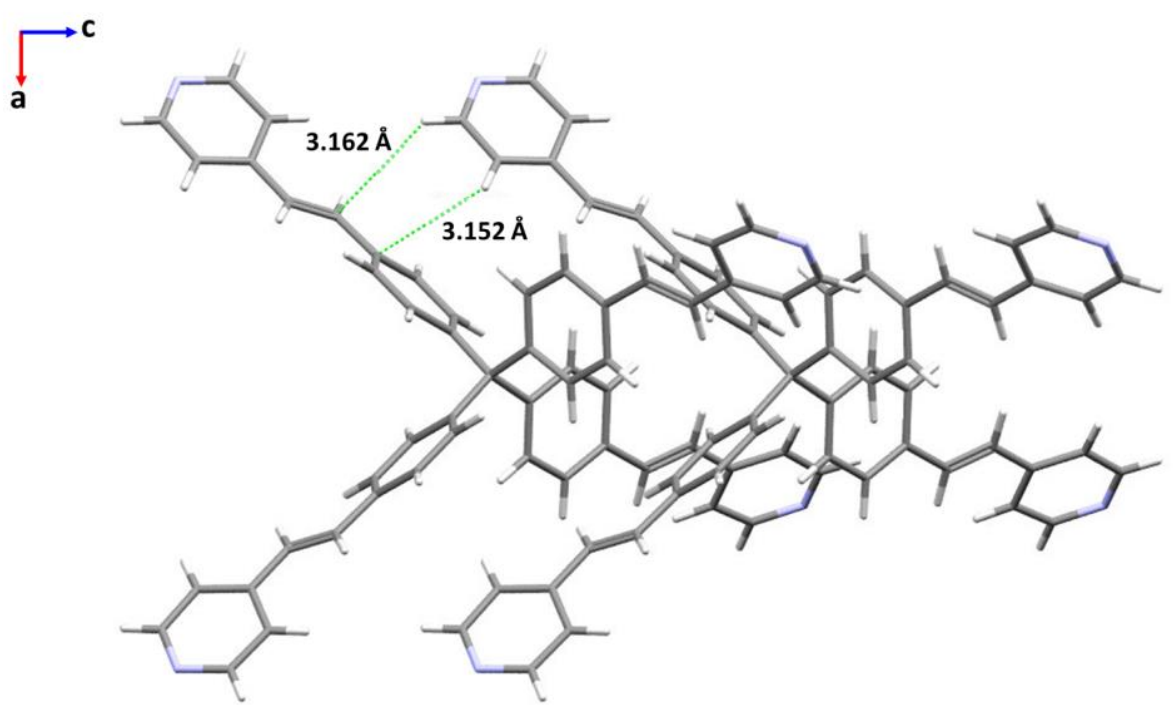

Figure S13. Partial molecular view of the crystalline structure of A2. The green dotted lines indicate the intermolecular distances between the pyridine ring and the styrene moieties. Colors: carbon - gray, nitrogen - blue, hydrogens - white. Crystallographic data (also deposited at the Cambridge Crystallographic Date Centre (CCDC) as CCDC 1907985).

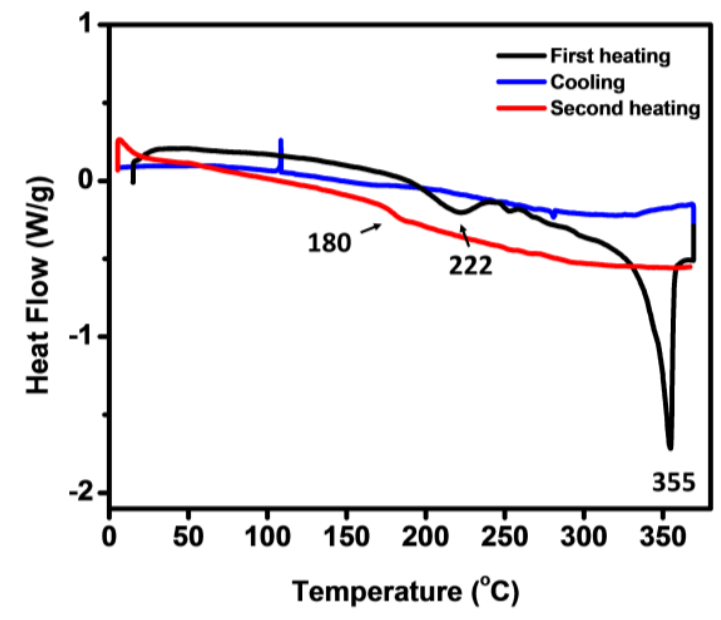

Figure S14. DSC heat-cool-heat thermogram of dry $\mathbf{A}_{2}$ powder at a heating rate of $10{ }^{\circ} \mathrm{C} / \mathrm{min}$ and cooling rate of $5{ }^{\circ} \mathrm{C} / \mathrm{min}$ under $\mathrm{N}_{2}$ flow. The thermogram of the first heating run shows two endothermic peaks at 222 ${ }^{\circ} \mathrm{C}$ and $355^{\circ} \mathrm{C}$. A glass transition at $\mathrm{T}_{\mathrm{g}}=180{ }^{\circ} \mathrm{C}$ is observed in the second heating run. 

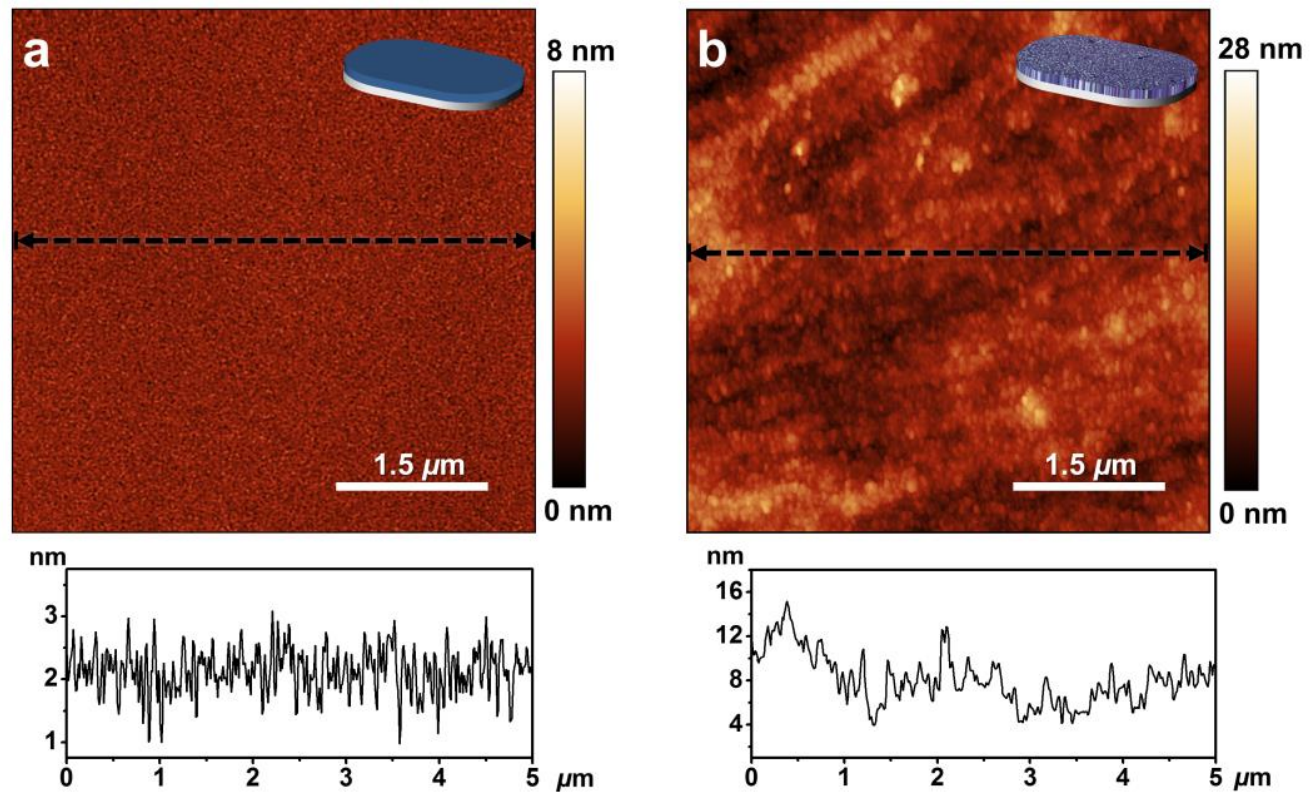

Figure S15. Representative AFM topography and height profiles of $\mathbf{S} \_\mathbf{A}_{2}$ (a) and $\mathbf{S} \_\mathbf{A}_{2} \cdot \mathbf{D}$ (b) on silicon. The RMS $\left(\mathbf{S}_{q}\right)$ for $\mathbf{S} \_\mathbf{A}_{2}$ is $\sim 0.5 \mathrm{~nm}$ for the $5 \mu \mathrm{m} \times 5 \mu \mathrm{m}$ image. Generation of $\mathbf{S} \_\mathbf{A}_{2} \cdot \mathbf{D}$ raises the roughness of the film to $\sim 2 \mathrm{~nm}$. $\mathrm{S}_{q}$ was measured over a $1.5 \mu \mathrm{m} \times 1.5 \mu \mathrm{m}$ area. The height profiles (bottom) measured along the black line in the corresponding topography image (top).

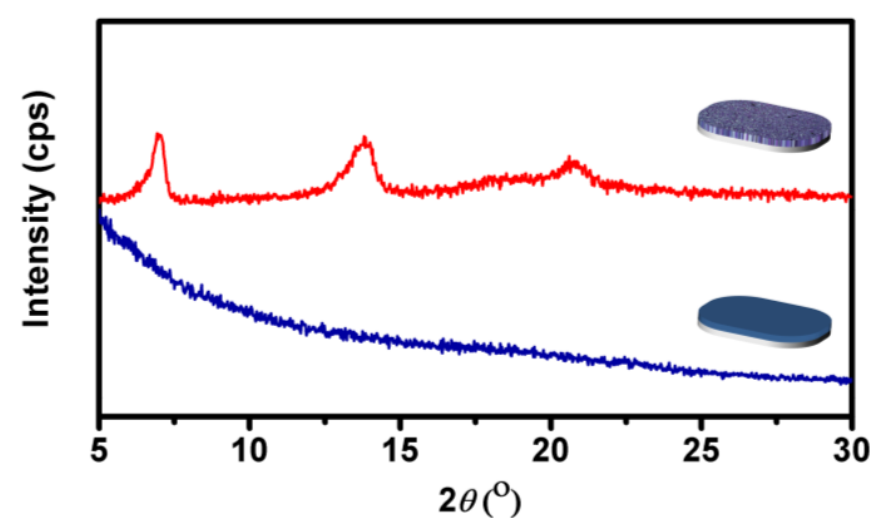

Figure S16. Reflection XRD patterns of $\mathbf{S} \_\mathbf{A}_{2}$ (blue) and $\mathbf{S} \_\mathbf{A}_{2} \cdot \mathbf{D}$ (red) on a $\operatorname{Si}(100)$ substrate showing that the amorphous-to-crystalline transformation has occurred. 


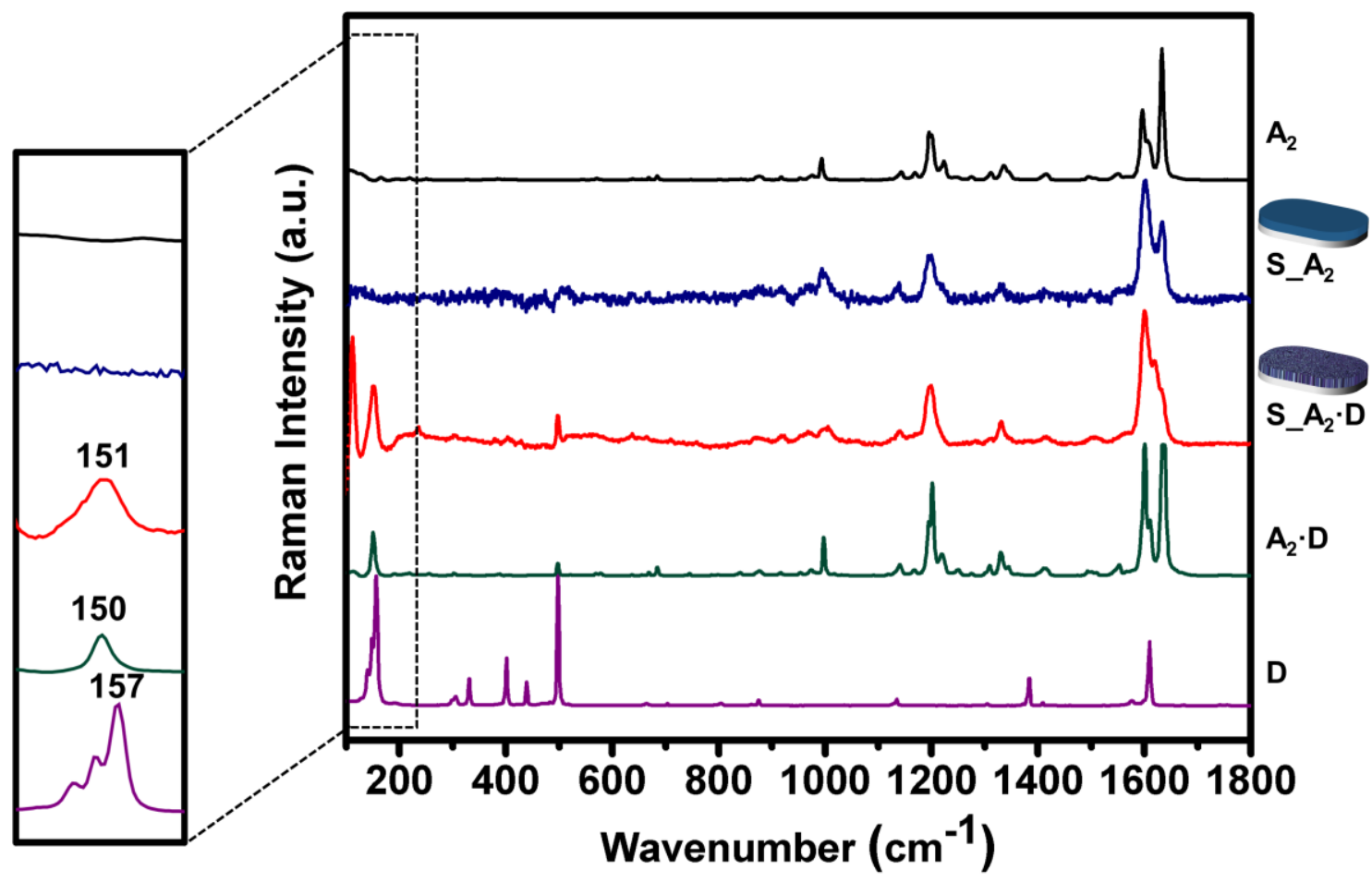

Figure S17. Normalized Raman spectra of $\mathbf{S} \_\mathbf{A}_{2}$ (blue) and $\mathbf{S} \_\mathbf{A}_{2} \cdot \mathbf{D}$ (red) on quartz substrates (excitation at $633 \mathrm{~nm}$ ) compared to the Raman spectra of powders of $\mathbf{A}_{2}$ (black), $\mathbf{D}$ (purple) and $\mathbf{\mathbf { A } _ { 2 }} \cdot \mathbf{D}$ cocrystal (green). The enlargement of the low-energy region shows the emergence of a band at $150 \mathrm{~cm}^{-1}$ on $\mathbf{S} \_\mathbf{A}_{2} \cdot \mathbf{D}$ film and compares its position relative to the $\mathrm{C}-\mathrm{I}$ stretch vibration of $\mathbf{D}\left(157 \mathrm{~cm}^{-1}\right)$ and $\mathbf{A} 2 \cdot \mathbf{D}\left(150 \mathrm{~cm}^{-1}\right)$. Strong fluorescent interference did not allow us to follow the amorphous-to-crystalline process in situ. 
a Optical microscopy
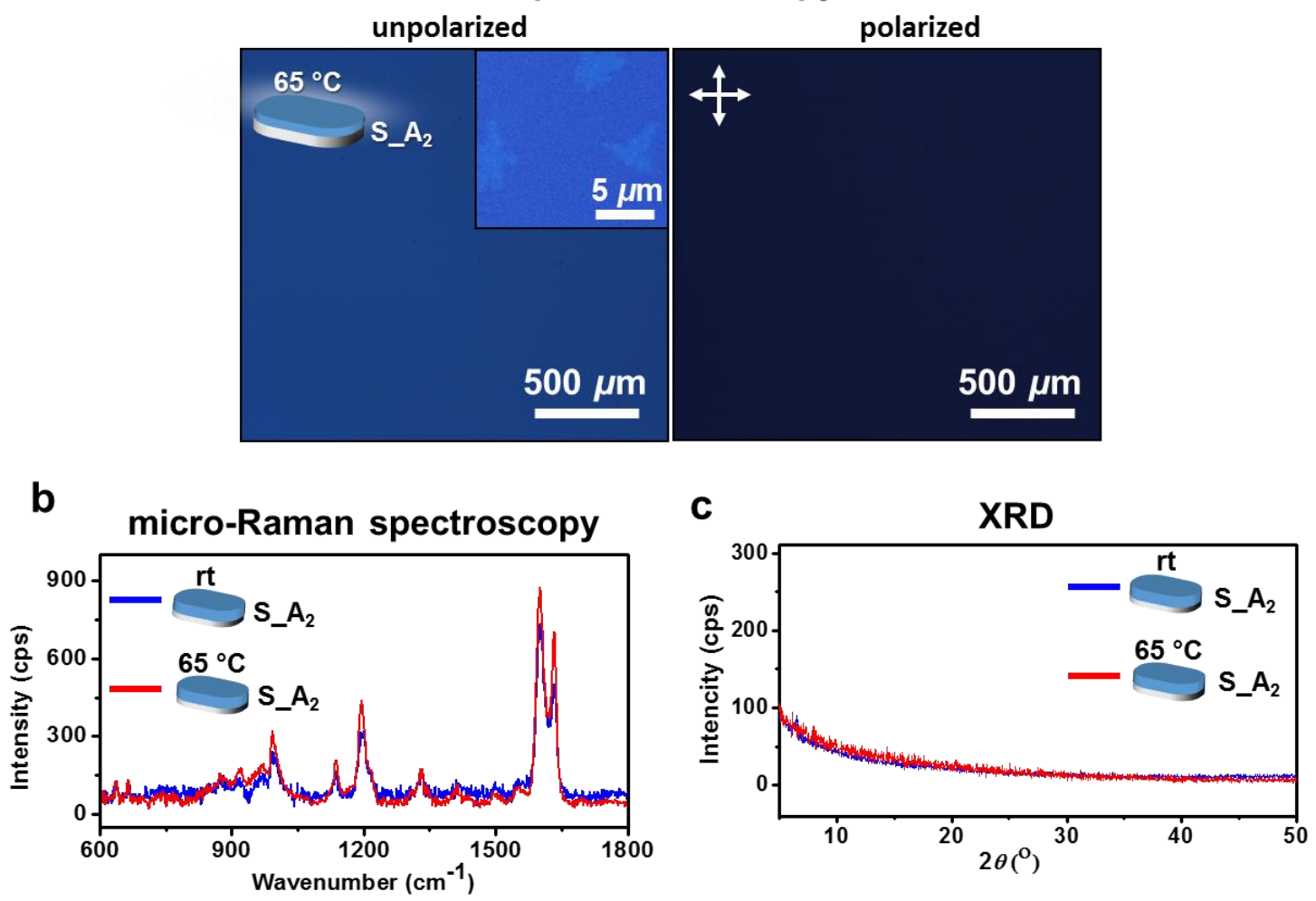

Figure S18. Characterization of thermally treated $\mathbf{S} \_\mathbf{A}_{2}$ in the absence of $\mathbf{D}$. $\mathbf{S} \_\mathbf{A}_{\mathbf{2}}$ was heated in an oven at $65{ }^{\circ} \mathrm{C}$ for $12 \mathrm{~h}$. (a) Optical micrographs showing faintly visible some structures in the thermally treated $\mathbf{S} \_\mathbf{A}_{2}$ on silicon, viewed without polarization (left) and between crossed polarizers (right) in a reflection mode. (b) Raman spectra of $\mathbf{S} \_\mathbf{A} 2$ on a quartz substrate before (blue) and after (red) heating with excitation at $633 \mathrm{~nm}$. (c) Reflection XRD patterns of $\mathbf{S} \_\mathbf{A}_{2}$ on a $\operatorname{Si}(100)$ substrate before (blue) and after (red) heating. 


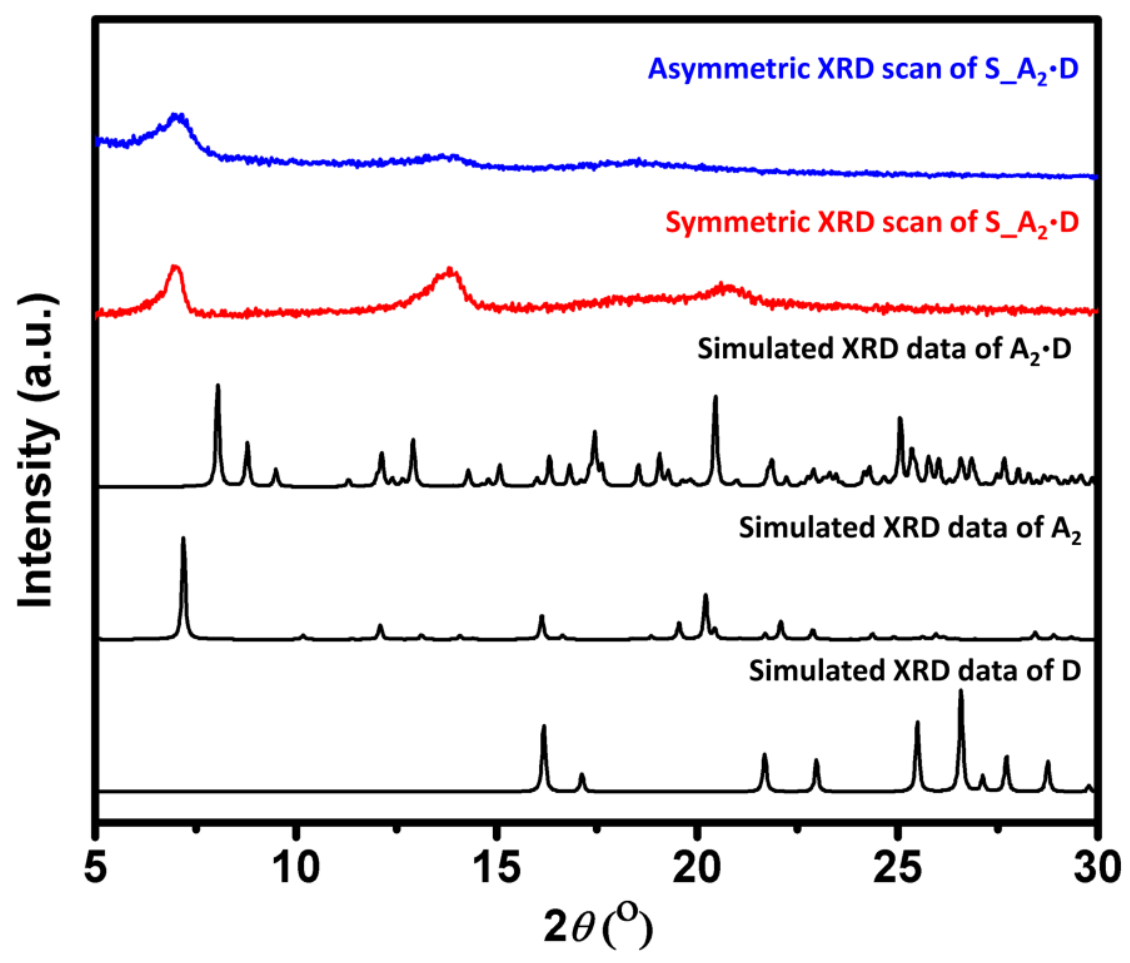

Figure S19. Reflection XRD patterns of $\mathbf{S} \_\mathbf{A} 2 \cdot \mathbf{D}$ on a $\mathbf{S i}(100)$ substrate measured in a symmetric (red) and asymmetric (blue) modes, and compared to the simulated XRD patterns of a $\mathbf{A}_{\mathbf{2}} \cdot \mathbf{D}, \mathbf{A}_{\mathbf{2}}$ and $\mathbf{D}$ single cocrystal grown from solution (black).

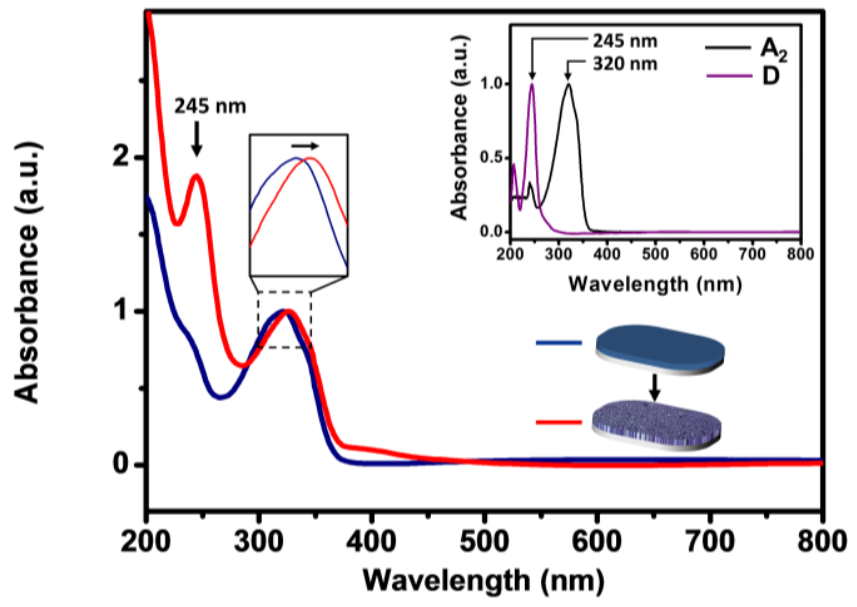

Figure S20. Normalized absorption spectra of $\mathbf{S} \_\mathbf{A}_{2}$ (blue) and S_A2 $\cdot \mathbf{D}$ (red) on quartz. The peak at $\lambda=245$ $\mathrm{nm}$ is due to the incorporation of compound $\mathbf{D}$ into $\mathbf{S} \_\mathbf{A}_{2}$ (c.f. the absorption spectra of $\mathbf{A}_{2}$ and $\mathbf{D}$ in solution, inset). Wavelength red shift of $\sim 5 \mathrm{~nm}$ of the $\pi-\pi^{*}$ transition of $\mathbf{A}_{2}$ in $\mathbf{S} \_\mathbf{A}_{2} \cdot \mathbf{D}$ is marked with a dashed box and indicated by an arrow. 


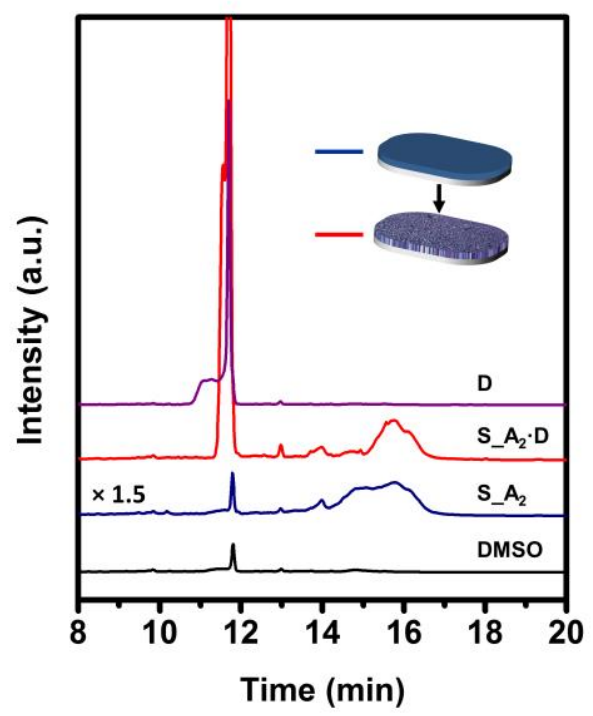

Figure S21. Reverse-phase HPLC (RP-HPLC) analysis of $\mathbf{S} \_\mathbf{A}_{2}$ (blue), $\mathbf{S} \_\mathbf{A} \mathbf{2} \cdot \mathbf{D}$ (red) and $\mathbf{D}$ (purple). The chromatograms were obtained by dissolving the deposited organic materials in DMSO (black). The ratio of the areas of the peaks of $\mathbf{A}_{\mathbf{2}}$ and $\mathbf{D}$ in the $\mathbf{S} \_\mathbf{A}_{\mathbf{2}} \cdot \mathbf{D}$ chromatogram is 1:4.2.

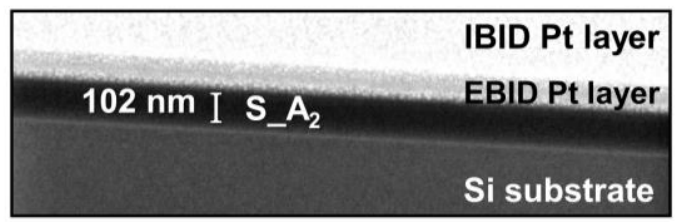

Figure S22. SEM micrograph of a cross section of a FIB-milled $\mathbf{S} \_\mathbf{A}_{2}$ on silicon. To protect $\mathbf{S} \_A_{2}$ from FIBinduced damage, the region of the cross section was coated with a platinum protective layer. IBID $=$ ionbeam induced deposition; EBID = electron-beam induced deposition. 

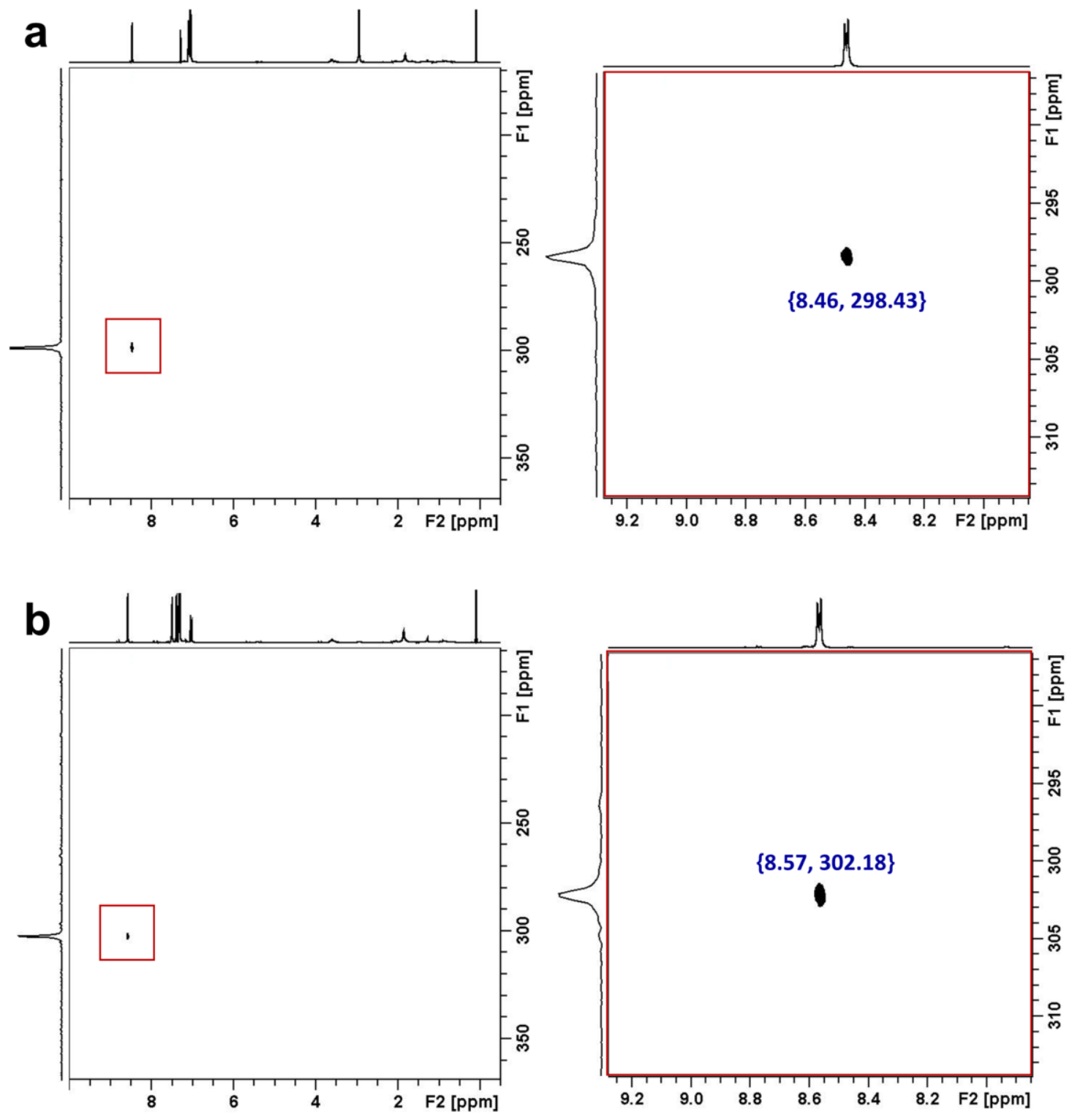

Figure S23. ${ }^{1} \mathrm{H}-{ }^{15} \mathrm{~N}$ HMQC NMR plots of (a) $\mathbf{A}_{1}$ and (b) $\mathbf{A}_{2}\left(16.8 \mathrm{mM}, 1.6 \%\right.$ (v/v) $\left.\mathrm{MeOD} / \mathrm{CDCl}_{3}\right)$. 
Table S1 Raman band assignment ${ }^{\mathrm{S} 19}$ of powders of $\mathbf{A} \mathbf{1}, \mathbf{A} \mathbf{2}$ and $\mathbf{D}, \mathbf{S} \_\mathbf{A} \mathbf{1}$ and $\mathbf{S} \_\mathbf{A} 2$ on a quartz substrate, cocrystals grown from solution of $\mathbf{A}_{\mathbf{1}} \cdot \mathbf{D}$ and $\mathbf{A}_{2} \cdot \mathbf{D}$, and cocrystals $\mathbf{S} \_\mathbf{A}_{1} \cdot \mathbf{D}$ and $\mathbf{S} \_\mathbf{A} 2 \cdot \mathbf{D}$ grown on a quartz substrate. ${ }^{a, b}$

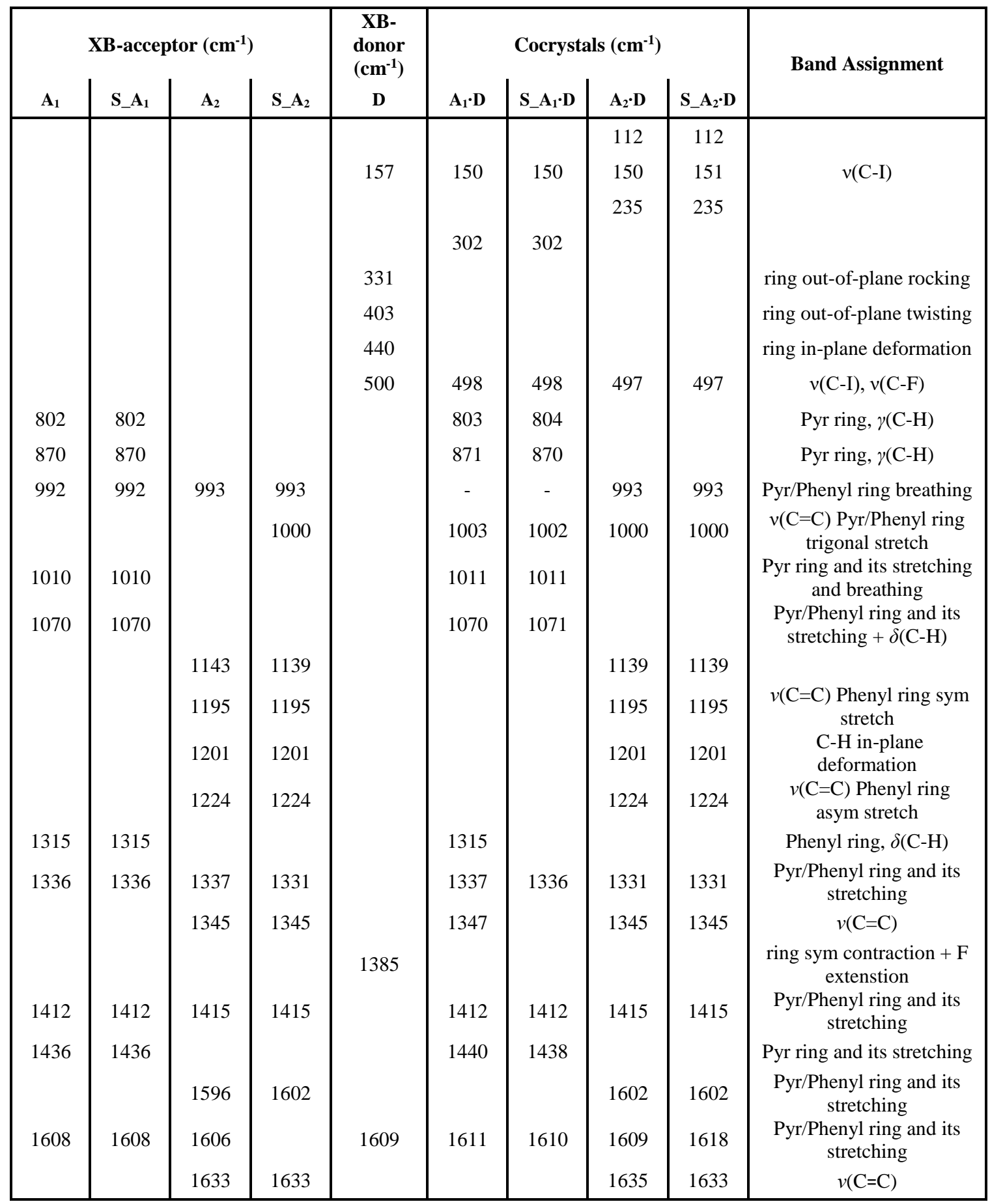

${ }^{a}$ Excitation at $632.8 \mathrm{~nm}$.

${ }^{b}$ The peak positions were extracted by a Lorentzian fit of the corresponding spectrum. 
Table S2 Field-desorption mass spectroscopy (FD-MS) analysis of $\mathbf{S} \_\mathbf{A} 1 \cdot \mathbf{D}$ and $\mathbf{S} \_\mathbf{A} \cdot \mathbf{D} \cdot \mathbf{D}^{\mathrm{a}, \mathrm{b}}$

\begin{tabular}{lccc} 
& $\mathbf{A}_{\mathbf{1}}(741.39)$ & $\mathbf{A}_{\mathbf{2}}(732.57)$ & $\mathbf{D}(401.84)$ \\
\hline S_A $\mathbf{A} \cdot \mathbf{D}$ & 741.54 & - & 401.84 \\
& & & \\
$\mathbf{S} \mathbf{S A}_{\mathbf{2}} \cdot \mathbf{D}$ & - & 732.47 & 401.86 \\
\hline
\end{tabular}

${ }^{a} \mathbf{S} \_\mathbf{A}_{1} \cdot \mathbf{D}$ and $\mathbf{S} \_\mathbf{A}_{2} \cdot \mathbf{D}$ were dissolved in $\mathrm{CHCl}_{3}$ and the solutions were analyzed by FD-MS.

${ }^{b}$ Theoretical $\mathrm{m} / z$ values of $\mathbf{A}_{\mathbf{1}}, \mathbf{A}_{\mathbf{2}}$ and $\mathbf{D}$ are shown in parentheses.

Table S3 Comparison of Young's modulii and adhesion ${ }^{a}$ forces between the silicon AFM tip and surface of $\mathbf{S} \_\mathbf{A}_{1}$ and $\mathbf{S} \_\mathbf{A}_{2}$ on silicon before and after heating at $65{ }^{\circ} \mathrm{C}$ and after exposure to the vapors of $\mathbf{D}$ at $65^{\circ} \mathrm{C}$ for $12 \mathrm{~h}$.

\begin{tabular}{|c|c|c|c|c|c|c|}
\hline & S_A $\mathbf{A}_{1}$ & S_A $A_{1\left(65^{\circ} \mathrm{C}\right)}$ & S_A $A_{1} \cdot \mathbf{D}$ & $\mathbf{S} \_A_{2}$ & $\mathbf{S} \_A_{2}\left(65^{\circ} \mathrm{C}\right)$ & S_A_ $\cdot \mathbf{D}$ \\
\hline $\begin{array}{l}\text { Young's } \\
\text { modulus (GPa) }\end{array}$ & $9.1 \pm 0.8$ & $4.5 \pm 0.3$ & $10 \pm 5$ & $9.5 \pm 0.9$ & $9.5 \pm 2$ & $4.9 \pm 0.7$ \\
\hline Adhesion (nN) & $87 \pm 3$ & $43 \pm 2$ & $67 \pm 19$ & $23 \pm 1$ & $23 \pm 2$ & $14 \pm 2$ \\
\hline
\end{tabular}

${ }^{a}$ Scanning the surfaces under dry $\mathrm{N}_{2}$ purge did not change the values of adhesion force from those obtained under ambient conditions. 


\section{References}

S1 P. Pelikán, M. Čeppan and M. Liška, Applications of Numerical Methods in Molecular Spectroscopy, Boca Raton: CRC Press Florida, 1993.

S2 B. Pittenger, N. Erina and C. Su, Nanomechanical Analysis of High Performance Materials, Tiwari, A., Ed.; Dordrecht: Springer Netherlands, 2014.

S3 D. Nečas and P. Klapetek, Cent. Eur. J. Phys., 2012, 10, 181-188.

S4 Gaussian 09, Revision E.01, M. J. Frisch, G. W. Trucks, H. B. Schlegel, G. E. Scuseria, M. A. Robb, J. R. Cheeseman, G. Scalmani, V. Barone, B. Mennucci, G. A. Petersson, H. Nakatsuji, M. Caricato, X. Li, H. P. Hratchian, A. F. Izmaylov, J. Bloino, G. Zheng, J. L. Sonnenberg, M. Hada, M. Ehara, K. Toyota, R. Fukuda, J. Hasegawa, M. Ishida, T. Nakajima, Y. Honda, O. Kitao, H. Nakai, T. Vreven, J. A. Montgomery, Jr., J. E. Peralta, F. Ogliaro, M. Bearpark, J. J. Heyd, E. Brothers, K. N. Kudin, V. N. Staroverov, R. Kobayashi, J. Normand, K. Raghavachari, A. Rendell, J. C. Burant, S. S. Iyengar, J. Tomasi, M. Cossi, N. Rega, J. M. Millam, M. Klene, J. E. Knox, J. B. Cross, V. Bakken, C. Adamo, J. Jaramillo, R. Gomperts, R. E. Stratmann, O. Yazyev, A. J. Austin, R. Cammi, C. Pomelli, J. W. Ochterski, R. L. Martin, K. Morokuma, V. G. Zakrzewski, G. A. Voth, P. Salvador, J. J. Dannenberg, S. Dapprich, A. D. Daniels, Ö. Farkas, J. B. Foresman, J. V. Ortiz, J. Cioslowski, and D. J. Fox, Gaussian, Inc., Wallingford CT, 2009.

S5 (a) J. P. Perdew, K. Burke, M. Ernzerhof, Phys. Rev. Lett., 1996, 77, 3865-3868;

(b) J. P. Perdew, K. Burke, M. Ernzerhof, Phys. Rev. Lett., 1997, 78, 1396.

S6 (a) S. Grimme, J. Antony, S. Ehrlich, H. Kreig, J. Chem. Phys., 2010, 132, 154104;

(b) T. Schwabe, S. Grimme, Acc. Chem. Res., 2008, 41, 569-579; (c) T. Schwabe, S. Grimme, Phys. Chem. Chem. Phys., 2007, 9, 3397-3406; (d) S. Grimme, J. Comput. Chem., 2006, 27, 1787-1799.

S7 S. Grimme, S. Ehrlich, L. Goerigk, J. Comput. Chem., 2011, 32, 1456-1465.

S8 (a) E. R. Johnson, A. D. Becke, J. Chem. Phys., 2006, 124, 174104; (b) E. R. Johnson, A. D. Becke, J. Chem. Phys., 2005, 123, 024101.

S9 J. Klimě̌, A. Michaelides, J. Chem. Phys., 2012, 137, 120901. 
S10 (a) A. Schäfer, H. Horn, R. Ahlrichs, J. Chem. Phys., 1992, 97, 2571-2577; (b) A. Schäfer, C. Huber, R. Ahlrichs, J. Chem. Phys., 1994, 100, 5829-5835.

S11 (a) D. Andrae, U. Häußermann, M. Dolg, H. Stoll, H. Preuß, Theor. Chim. Acta, 1990, 77, 123-141; (b) M. Kaupp, P. Schleyer, H. Stoll, H. Preuss, J. Chem. Phys., 1991, 94, 1360-1366; (c) T. Leininger, A. Nicklass, W. Küchle, H. Stoll, M. Dolg, A. Bergner, Chem. Phys. Lett., 1996, 255, 274-280; (d) B. Metz, H. Stoll, M. Dolg, J. Chem. Phys., 2000, 113, 2563-2569; (e) F. Weigend, R. Ahlrichs, Phys. Chem. Chem. Phys., 2005, 7, 3297-3305.

S12 (a) B. I. Dunlap, J. Chem. Phys., 1983, 78, 3140-3142; (b) B. I. Dunlap, J. Mol. Struct., 2000, 529, 37-40.

S13 P. Bultinck, C. van Alsenoy, P. W. Ayers, C. D. Ramon, J. Chem. Phys., 2007, 126, 144111.

S14 A. M. W. Cargill Thompson, J. Hock, J. A. McCleverty, M. D. Ward, Inorg. Chim. Acta, 1997, 256, 331-334.

S15 G. M. Sheldrick, Acta Crystallogr., Sect. A: Found. Adv., 2015, 71, 3-8.

S16 G. M. Sheldrick, Acta Crystallogr., Sect. C: Struct. Chem., 2015, 71, 9-18.

S17 S. Shankar, O. Chovnik, L.J. W. Shimon, M. Lahav, M. E. van der Boom Cryst. Growth Des., 2018, 18, 1967-1977.

S18 A. Bondi, J. Phys. Chem., 1964, 68, 441-451.

S19 (a) J. H. S. Green, D. J. Harrison, Spectrochim. Acta A, 1977, 33, 193-197; (b) A. Topaçli, S. Akyüz, Spectrochim. Acta A 1995, 51, 633-641; (c) Z.Meić, H. Güsten, Spectrochim. Acta A, 1978, 34, 101-111; (d) G. Zerbi, S. Sandroni, Spectrochim. Acta A, 1968, 24, 511-528. 